\title{
Systematic literature review of reproductive outcome associated with residential proximity to polluted sites
}

Wahida Kihal-Talantikite ${ }^{1 *}$, Denis Zmirou-Navier ${ }^{2,3,4}$, Cindy Padilla ${ }^{5}$ and Séverine Deguen ${ }^{2,6}$

\begin{abstract}
This study aims to assess the evidence on adverse pregnancy outcome associated with living close to polluted industrial sites, and identify the strengths and weaknesses of published epidemiological studies. A systematic literature search has been performed on all epidemiological studies published in developed countries since 1990, on the association between residential proximity to industrial sites (hazardous waste sites, industrial facilities and landfill sites) and adverse pregnancy outcome (low birth weight, preterm birth, small for gestational age, intrauterine growth retardation, infant mortality, congenital malformation). Based on 41 papers, our review reveals an excess risk of reproductive morbidity. However, no studies show significant excess risk of mortality including fetal death, neonatal or infant mortality and stillbirth. All published studies tend to show an increased risk of congenital abnormalities, yet not all are statistically significant. All but two of these studies revealed an excess risk of low birth weight. Results for preterm birth, small for gestational age and intrauterine growth retardation show the same pattern. There is suggestive evidence from the post-1990 literature that residential proximity to polluted sites (including landfills, hazardous waste sites and industrial facilities) might contribute to adverse reproductive outcomes, especially congenital malformations and low birth weight - though not mortality. This body of evidence has limitations that impede the formulation of firm conclusions, and new, well-focused studies are called for. The review findings suggest that continued strengthening of rules governing industrial emissions as well as industrial waste management and improved land use planning are needed.
\end{abstract}

Keywords: Systematic review, Residential proximity, Polluted sites, Reproductive outcome, Geographic information systems (GIS)

\section{Background}

There is growing public and scientific concern regarding the adverse reproductive effects of environmental exposures occurring via three main pathways: contact with ambient air, soil, and drinking water [1, 2]. Most studies published to date have focused on exposure to trafficrelated air pollution [3], and several papers have revealed that living near freeways or roadways is associated with toxic effects on both fetus and infant [4-6]. Some studies have examined whether industrial pollution might

\footnotetext{
*Correspondence: wahida.kihal@live-cnrs.unistra.fr

1 LIVE UMR 7362 CNRS (Laboratoire Image Ville Environnement),

University of Strasbourg, 3 Rue de l'argonne, 6700 Strasbourg, France

Full list of author information is available at the end of the article
}

also alter human health among neighborhood residents [7]. Those who live near polluted sites may be exposed to chemicals released into the air (including off-site migration of gases, dust and chemicals bound to dust, especially during maintenance or transformation operations at the site), as well as through surface or groundwater contamination, or by direct contact with polluted soil. Indeed, these toxicants emanating from polluted sitesincluding heavy metals, and volatile and other organic compounds-have been reported to affect reproductive outcome around Hazardous Waste Sites (HWS), industrial facilities and landfills [2]. Moreover, the reproductive toxicity of these chemical pollutants has increasingly been documented by toxicological, experimental and animal studies [8]. For instance, some advanced biological 
mechanisms suggest that heavy metals (cadmium) may affect progesterone production by interfering with steroidogenesis, possibly disturbing endocrine function in pregnant women [9]. These endocrine disruptions constitute a relevant plausible mechanism for an effect on adverse reproductive outcome [10].

Assessment of exposure to emanations from polluted sites is tricky, mainly due to a lack of data on emissions and the cost of acquiring personal exposure data (including biomarkers or other personal data, such as behavioral patterns related to exposure). An alternative way of overcoming these difficulties lies in the use of indirect indicators measuring the proximity of polluted sites, and several types of indicators have been used for this purpose [11-13].

During the 1980s and 1990s, because of growing public awareness and concern about the potential adverse health effects of exposure to chemical contaminants emanating from polluted sites, developed countries drew up environmental laws and waste management guidance policies. For instance, in the United States the Comprehensive Environmental Response, Compensation, and Liability Act (CERCLA-also known as Superfund) [14] was set up in order to reduce emissions and protect the environment. This was followed by numerous reforms during the 1990s (e.g. the Pollution Prevention Act) [15]. A similar European Union Directive on Integrated Pollution Prevention and Control (IPPC) [16] offered waste management guidance-and was transposed into such national legislation as the ICPE (Installations Classées pour la Protection de l'Environnement) provision in France [17] and Pollution Protection and Control in England and Wales [18]. Implementation of these programs can play an important role in facilitating the cleanup and redevelopment of properties contaminated by hazardous substances. For example, CERCLA affords local government-through the acquisition of contaminated properties-an opportunity to evaluate and assess public safety needs and promote redevelopment projects that will protect and improve the health, environment, and economic well-being of their communities.

Despite improvements in the management of HWS and polluted facilities in developed countries since the 1990s, there is still a question mark as to whether studies may yet reveal excess risks of adverse pregnancy outcome around such sites. Moreover, the fast industrial expansion of emerging countries throughout the world raises the question of the environmental and public health consequences of this development pattern-perhaps its impact will resemble that observed in the 1950s to 1970 s in industrialized nations.
A systematic literature review was conducted in order to determine how proximity to environmental hazards impacts the health of neighboring populations, in terms of adverse pregnancy outcome.

The principal objective of the present study is to assess the current evidence on adverse pregnancy outcome associated with living near polluted sites, and to identify the strengths and weaknesses of epidemiological studies published in developed countries since the 1990s, when pollution prevention policies were in effect. An additional objective is to provide more information on the associated health risks with a view to suggesting future directions for research and providing evidence to enhance risk management policies.

\section{Methods}

A systematic literature search was conducted using the Pubmed platform, giving access to the Medline and Academic Search Complete databases, among articles published up to December 2016.

The search strategy followed the Preferred Reporting Items for Systematic reviews and Meta-Analyses (PRISMA) guidelines $[19,20]$ and was performed with the following keywords found in article titles:

(industry or industrial or industries or incinerator (s) or polluted site (s) or landfill or hazardous waste (s) or waste site (s) or dumpsites) AND (Fetal or neonatal or infant mortality or miscarriage or stillbirth (s) or infant death or neonatal death or abortion (s) or preterm or prematurity or pregnancy or reproductive or gestational or newborn or birth (s) or birth weight or congenital abnormalities or congenital or congenital abnormality or congenital malformation (s) or small for gestational age or intrauterine growth retardation or birthweight or offspring).

\section{Selection of studies}

At the first step, the inclusion criteria were peer-reviewed papers written in English and articles published after 1990 dealing with the impact of polluted sites on reproductive outcomes without restriction on geographical location (Fig. 1).

Papers presenting non-original studies (e.g. comments, case reports), papers that were published pre-1990 and papers addressing other subjects were ultimately excluded. In all, 77 of the 297 articles published were selected.

At the second step, abstracts of the 77 studies were screened manually by two independent experts (SD and WK, authors of this article); studies were retained if: 


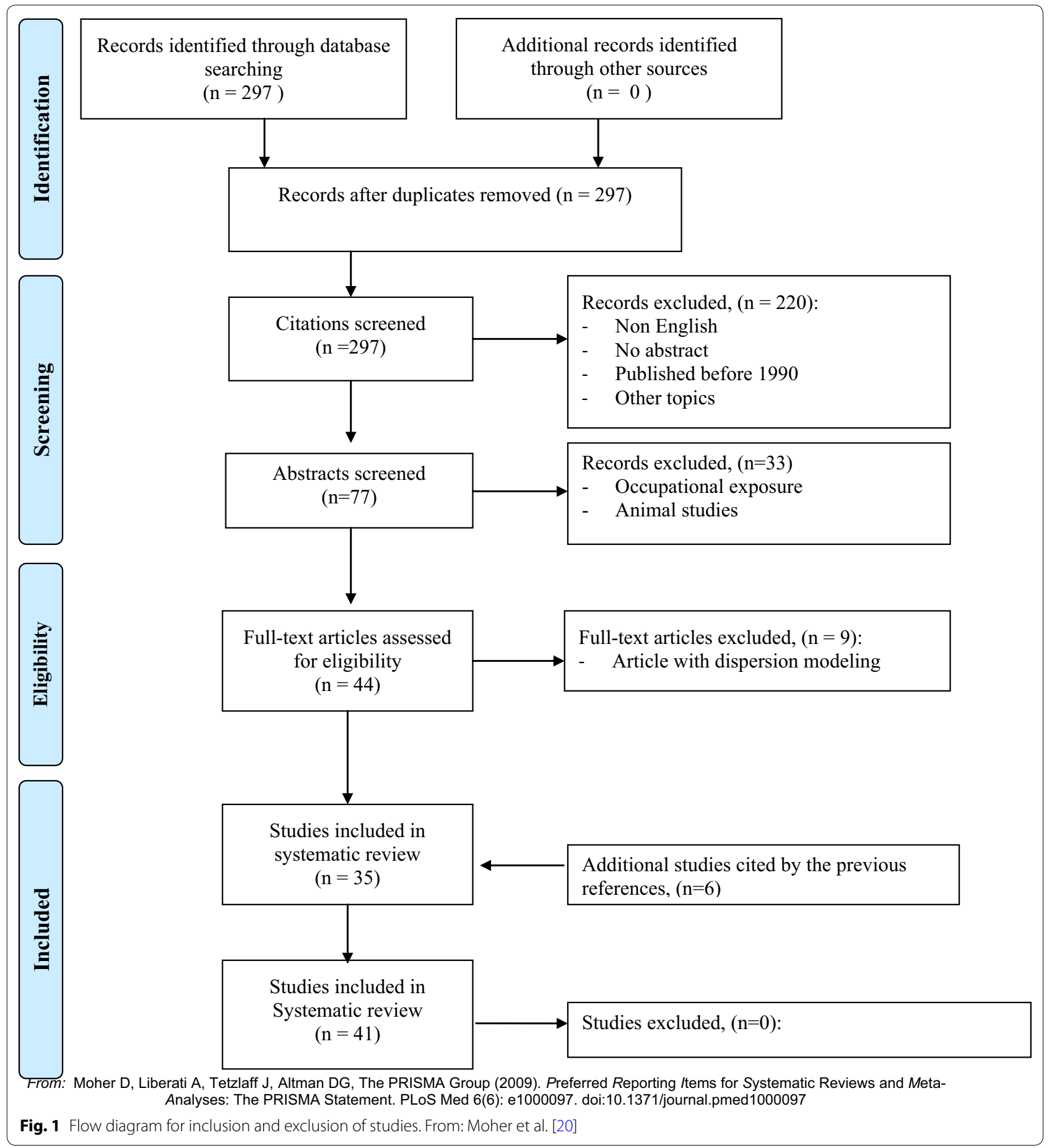

(i) they described the indicators measuring the proximity of polluted sites;

(ii) the source of pollution was residential (i.e. nonoccupational);

(iii) authors examined a relationship between a human reproductive outcome and a polluted site.
Full manuscripts of the remaining 45 articles (of the 297 initially selected) were thoroughly checked. Because we focused our paper on studies using GIS-based processing functions for spatial exposure assessment, 9 articles using dispersion modeling or interpolation techniques as an exposure assessment method were thus excluded. 
Ultimately, a total of 35 articles met the inclusion criteria for the systematic literature review.

Bibliographic reference lists of all included studies were searched manually. Six additional studies cited by the previous references were then included [21-26], resulting in a total of 41 papers that fit the inclusion criteria. Each is reviewed below.

\section{Extraction data}

For each study, the following information was extracted and reported in Tables 1 and 2: general Information (first author's name, date of study and country of origin), main study characteristics (study design, spatial unit, statistical methods, population definition, database, main findings), participant characteristics (information on confounders), exposure assessment methods and reproductive outcome measures (outcomes classification and definition).

The present paper comprises 5 sections. First section: "Bibliographic material" presents an outline of the different study designs, followed by the various categories of reproductive outcome related to residential proximity to polluted sites, and finally the environmental contaminations that were explored. The findings of this section are summarized in Tables 1, 2 and 3. Second section: GIS methodology presents an overview of analytical methods used to assess residential proximity to polluted sites using approaches based on GIS and according to type of polluted sites. The findings of this section are summarized in Table 4. Third section: Current evidence on the possible effects of proximity to polluted sites addresses the question of whether or not proximity to polluted sites can affect reproductive outcome. Fourth section is a discussion of the general methodological issues relevant to epidemiological investigation of the effects of proximity to polluted sites on reproductive outcome. Fifth section offers conclusions and recommendations for improving future research on these issues.

\section{Bibliographic material}

Tables 1 and 2 provides the characteristics of all the studies reviewed, by year of publication, type of study design, pregnancy outcome, exposure assessment and major findings and conclusions.

\section{Study location}

Most studies were conducted in the United States (18) $[12,13,22,23,27-40]$ and the UK (14) $[11,21,24,25$, 41-50]. We also found five studies conducted in continental Europe [1, 26, 51-53], two in Canada [54, 55] and two in Asia $[56,57]$ investigating whether living near a polluted site increases the risk of adverse reproductive outcome. Contrasted descriptions were revealed in term of study location, period of publication, outcomes and polluted sites of interest according to the design of the study (more details in "Study design" section).

\section{Design and database}

With the exception of a single descriptive geographical study [25] and eleven ecological studies [11, 21, 24, 27, $28,45,47-49,53,57]$, all papers analysed individual data, including ten cohort studies [29, 36, 42-44, 46, 50, 55, 56] and 18 case-control studies $[1,12,13,22,23,30-35,37-$ $40,51,52,54]$. Most databases were drawn from either congenital registers or birth certificates (see Table 3).

\section{Reproductive outcome}

The relation between maternal residence near sources of potential environmental hazard and pregnancy outcome has been investigated for a variety of outcomes. The first category, in number, is congenital malformations, encompassing studies of all congenital abnormalities combined [1, 11-13, 21-26, 30-39, 41, 45-48, 50, $52,55,57]$, specific abnormalities such as heart defects $[1,11-13,22,23,26,31,34-36,45-47,52,55]$, neural tube defects (NTD) $[1,11,12,35,39,45,47,52$, 55], central nervous system abnormalities [12, 23, 26, $36-38,52,57]$, oral defects $[11,12,23,35,37,41,45$, $47,52]$, chromosomal abnormalities [12, 13, 24, 33, 34, $37,46,49-51,55,57]$ and lethal congenital abnormalities $[42-44,56]$. The second most investigated category of outcome encompassed low birth weight (LBW) [21, $23,27-30,45,47,48,50,53-56]$, preterm birth (РTB) $[27,29,53-55]$, small for gestational age (SGA) $[53,54]$ and intrauterine growth retardation (IUGR) $[29,55]$. The third outcome category was death, including infant death $[30,56]$, neonatal $[36,42-44,56]$ or fetal death $[30,36,40,56]$, stillbirth $[42-45,47,48]$ and spontaneous abortion [21].

\section{Exposure assessment Sources of pollution}

Most frequently, the pollution sources were hazardous waste sites [12, 13, 22, 24, 25, 28, 30-35, 37-40, 55] or landfills [1, 11, 21, 26, 27, 41, 42, 45-47, 49-52, 54]. Fewer papers have examined residential proximity to industries [13, 22, 32, 33, 38, 39, 43, 48, 53, 57], municipal waste incinerators $[44,56]$, dumpsites $[29,36]$ or crematoriums [44]. One study encompassed environmental risks from across landfills, dumpsites, hazard waste sites and industrial sites [23] (see Table 4).

\section{Exposure classification}

Most studies have either considered sites generically (irrespective of their characteristics or the categories of pollutants emitted), or taken into account their specific characteristics. 


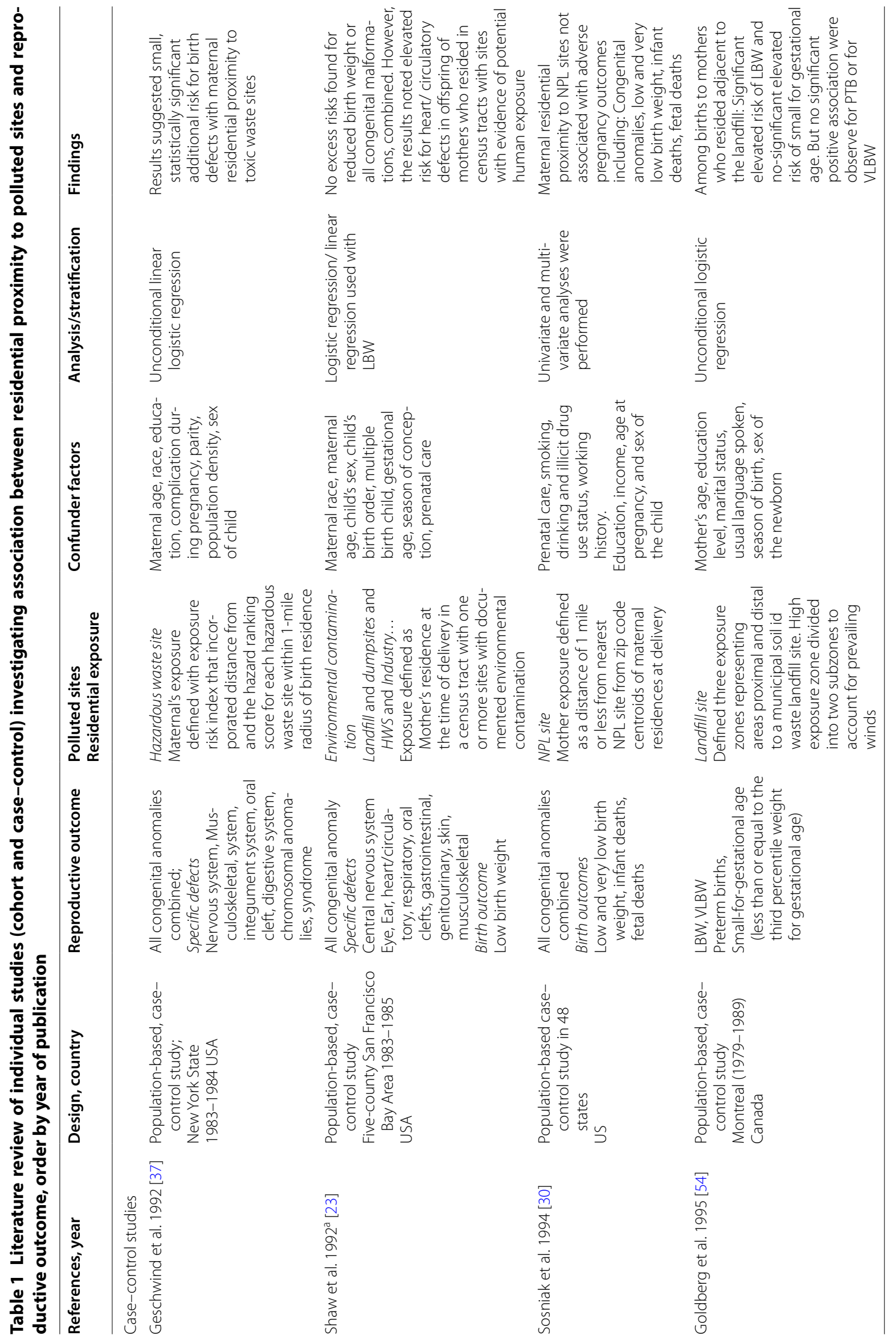




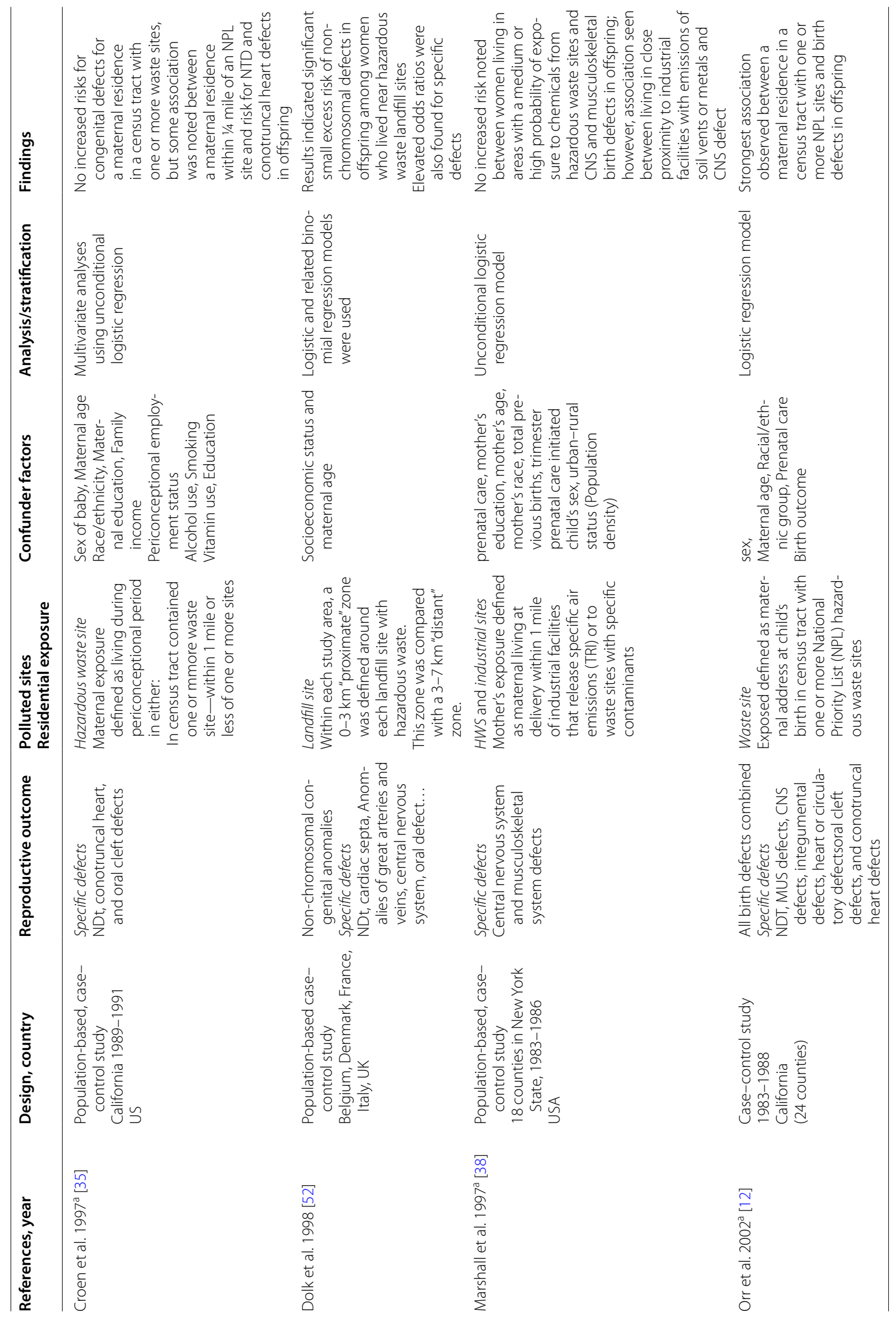




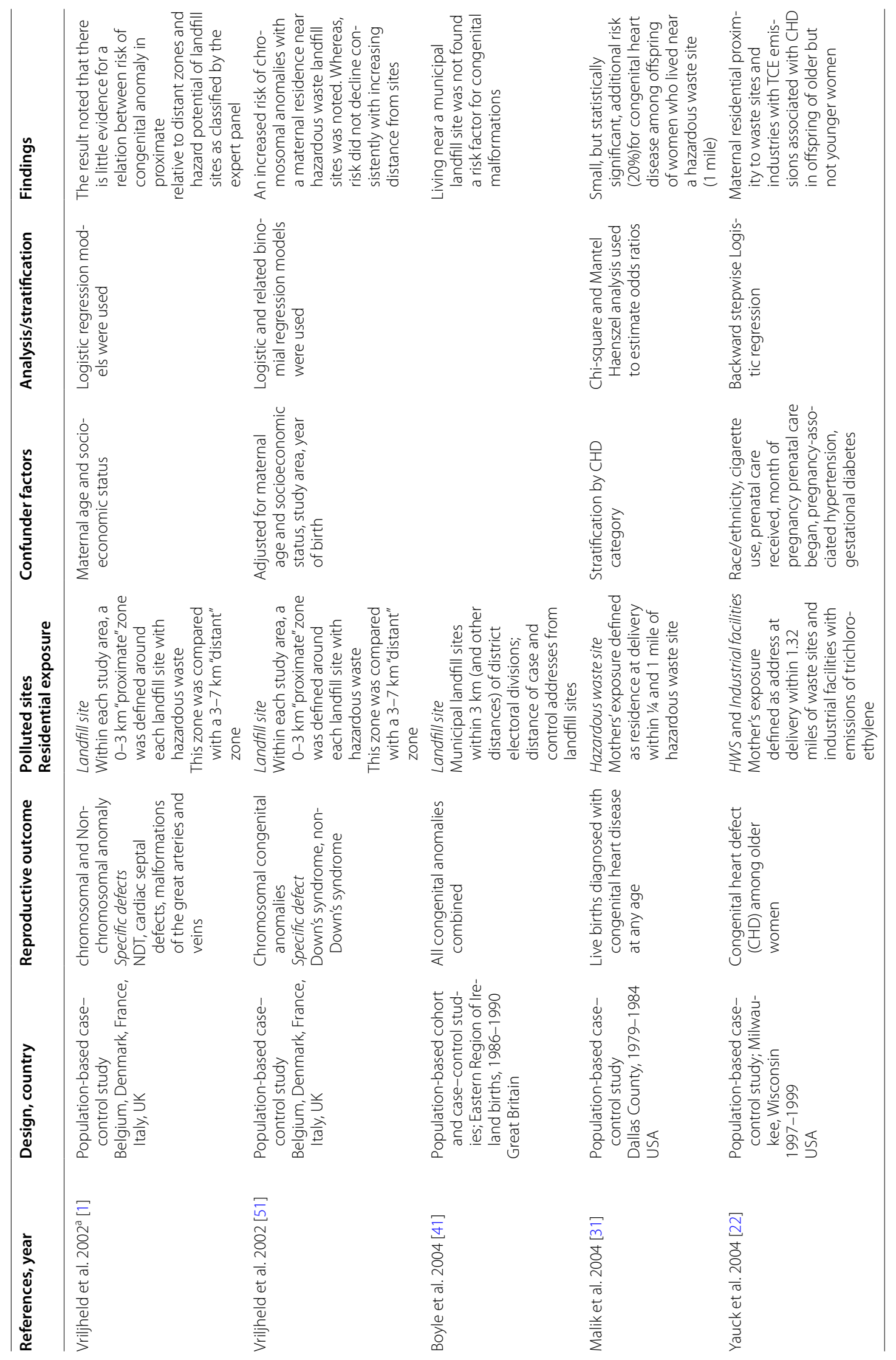




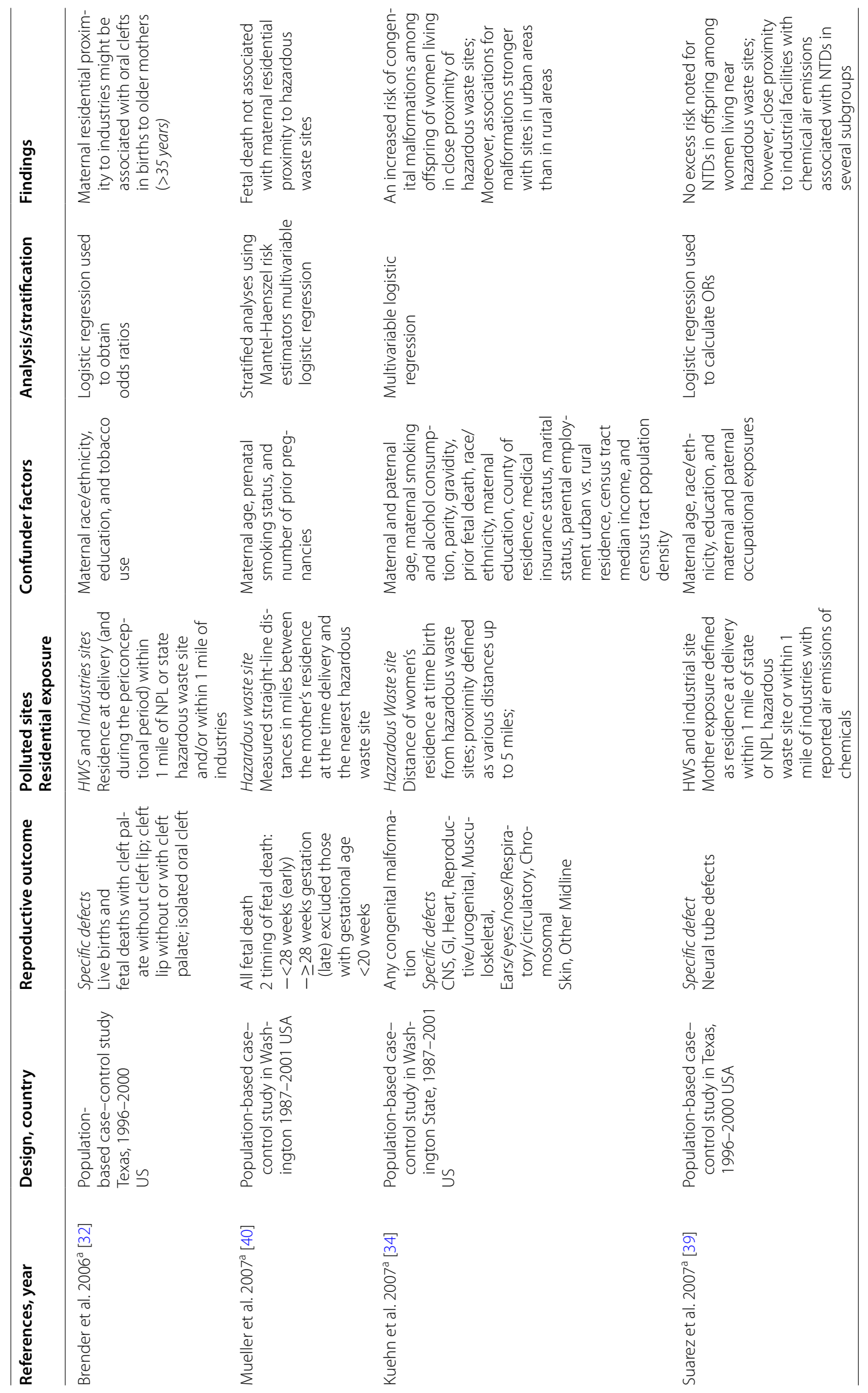




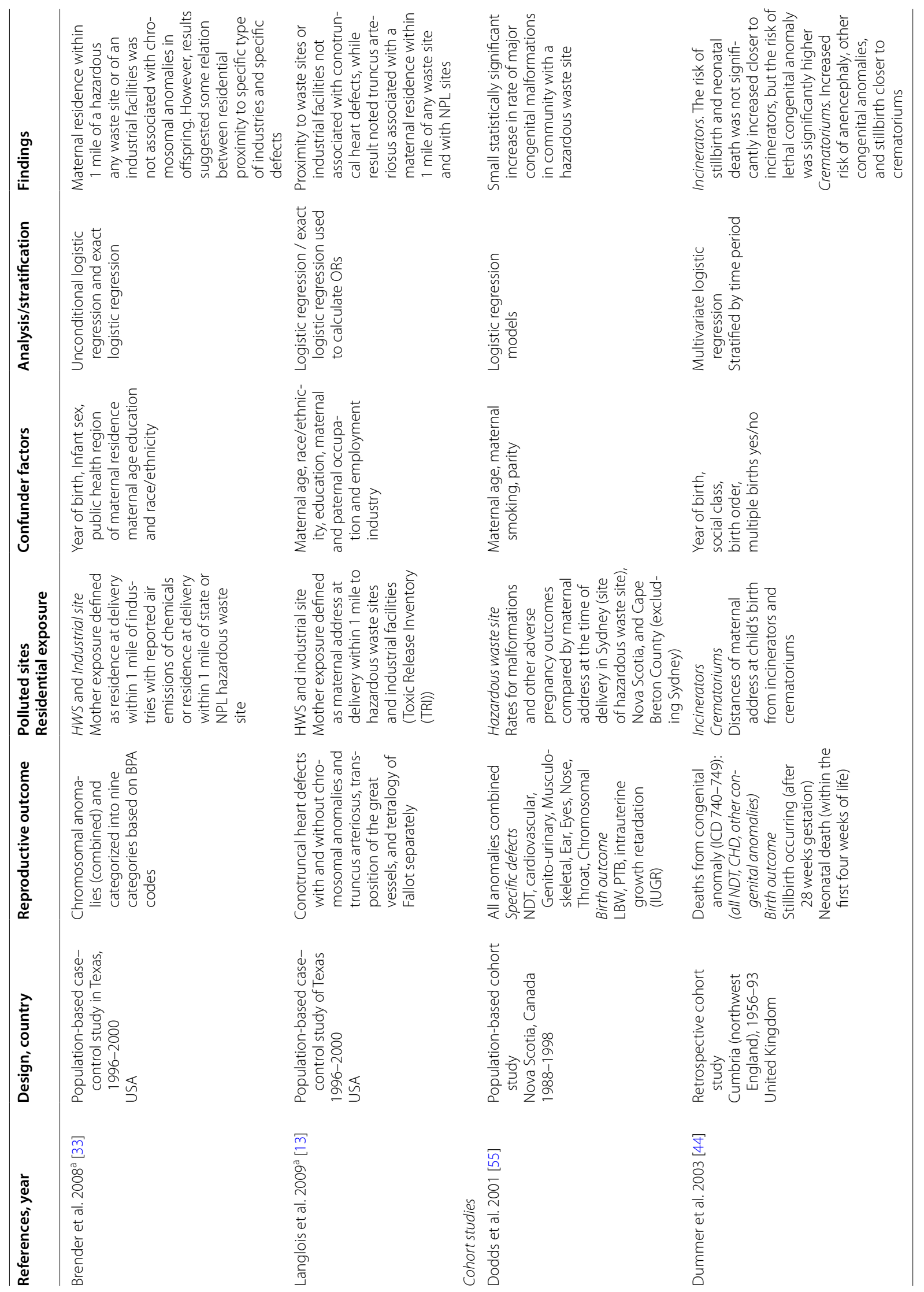




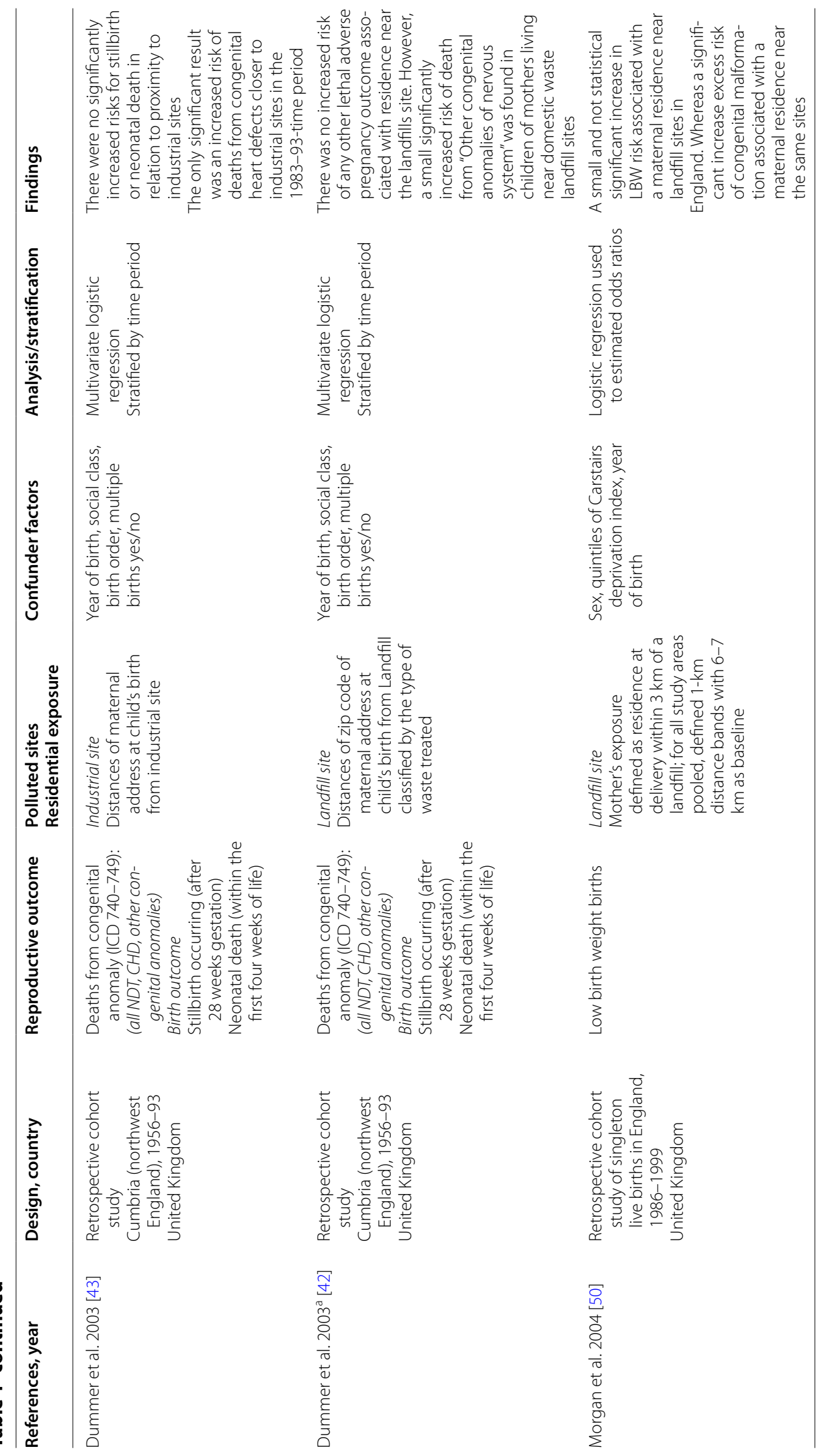




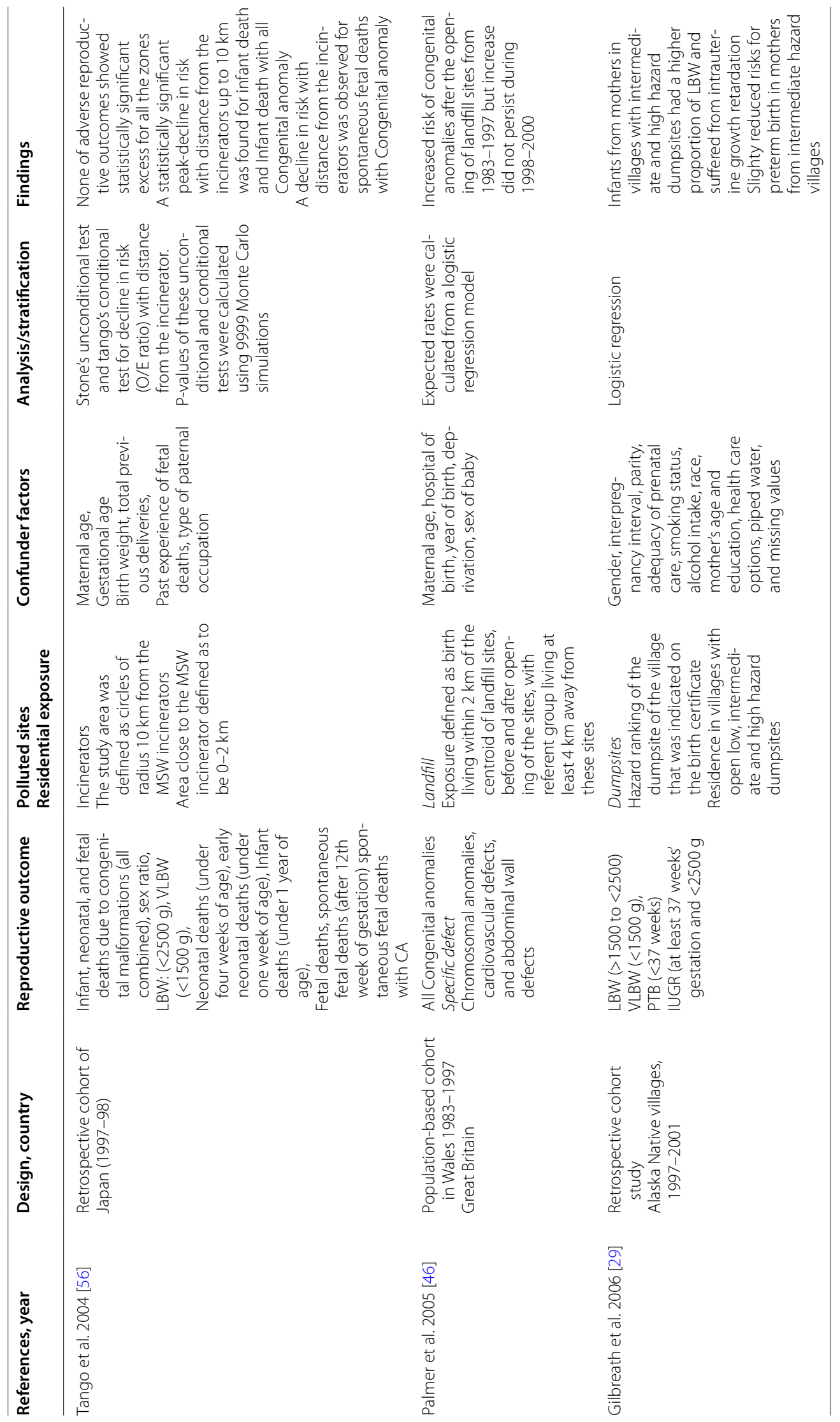




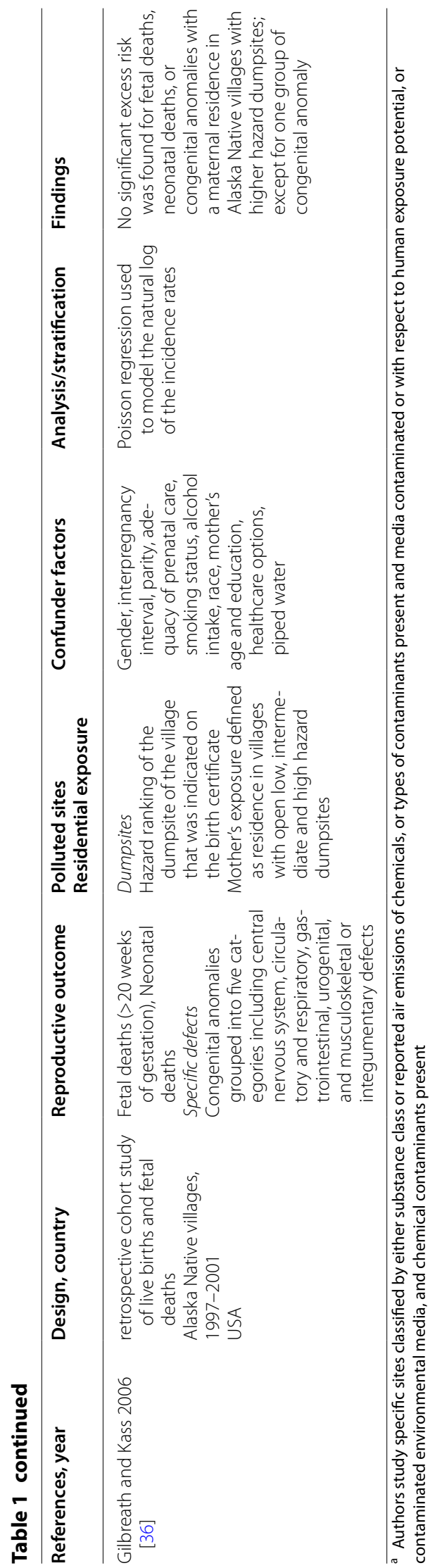




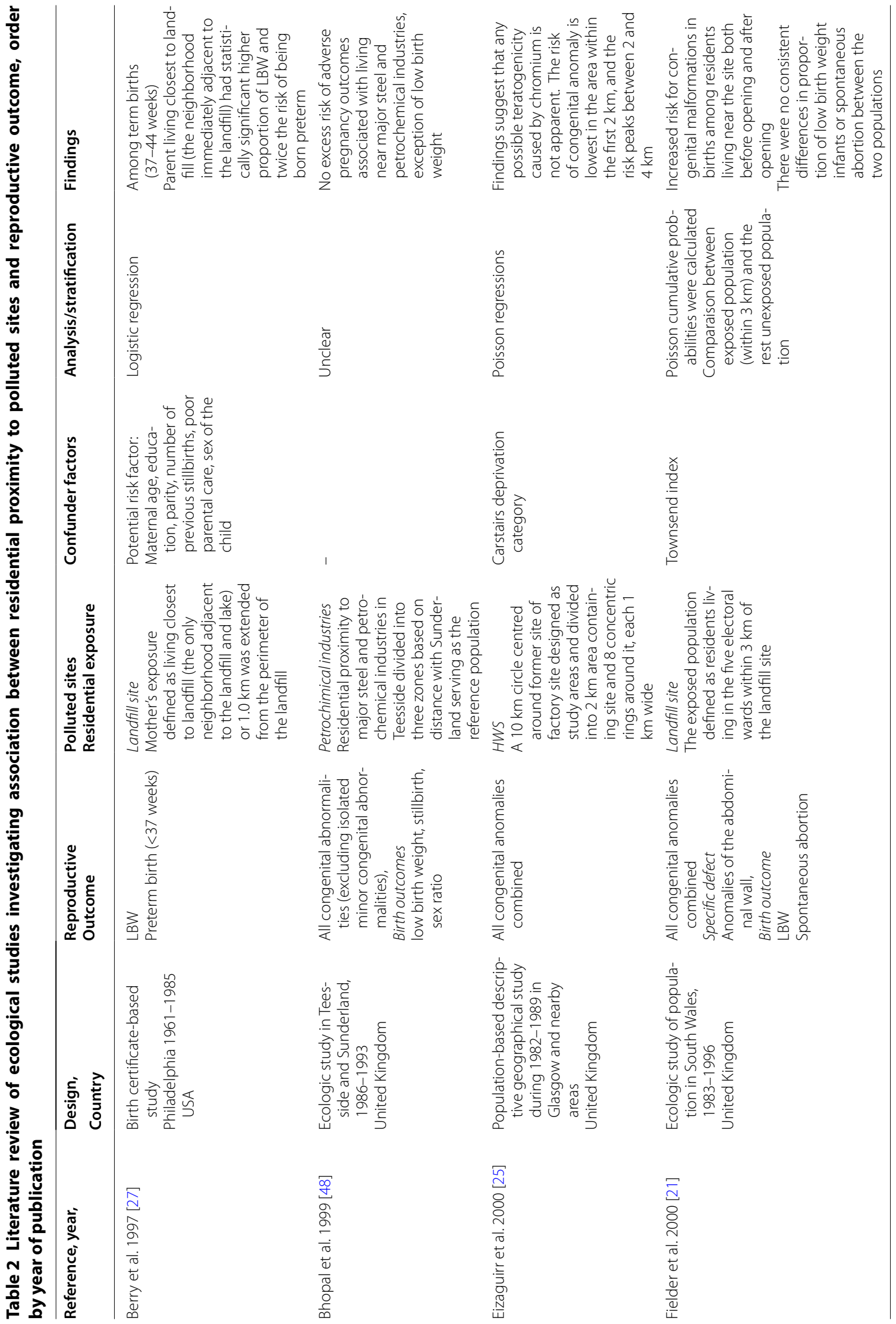




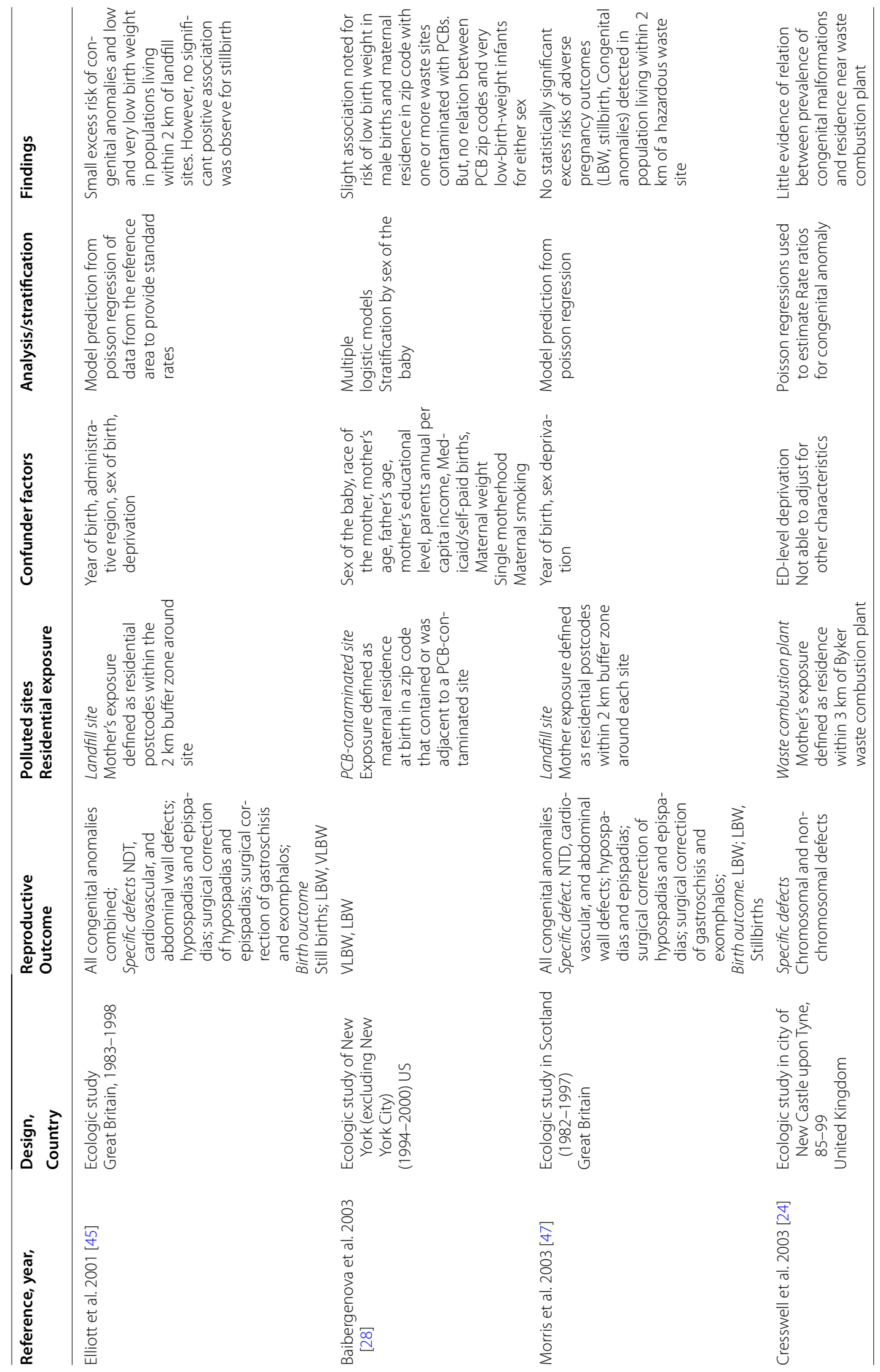




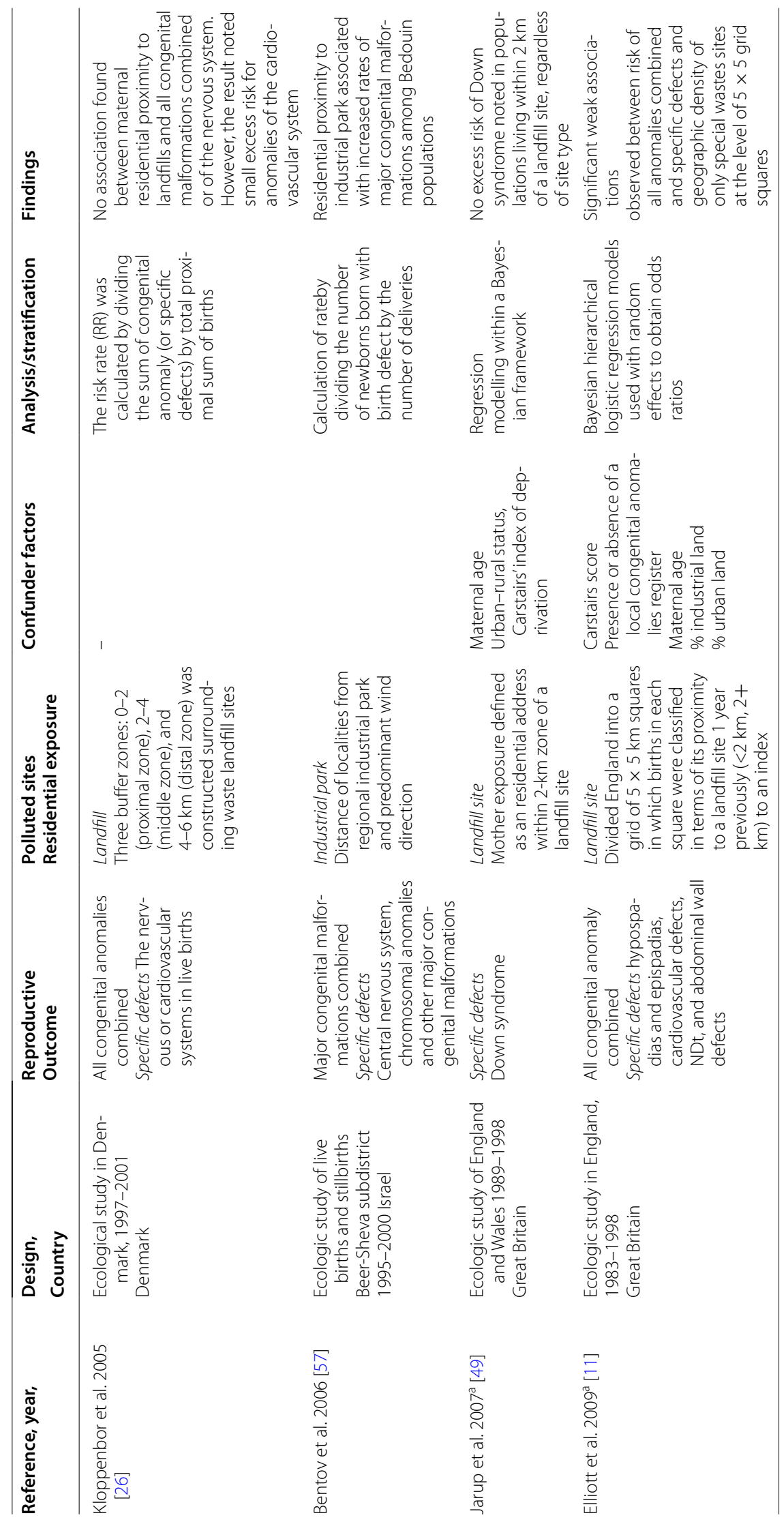




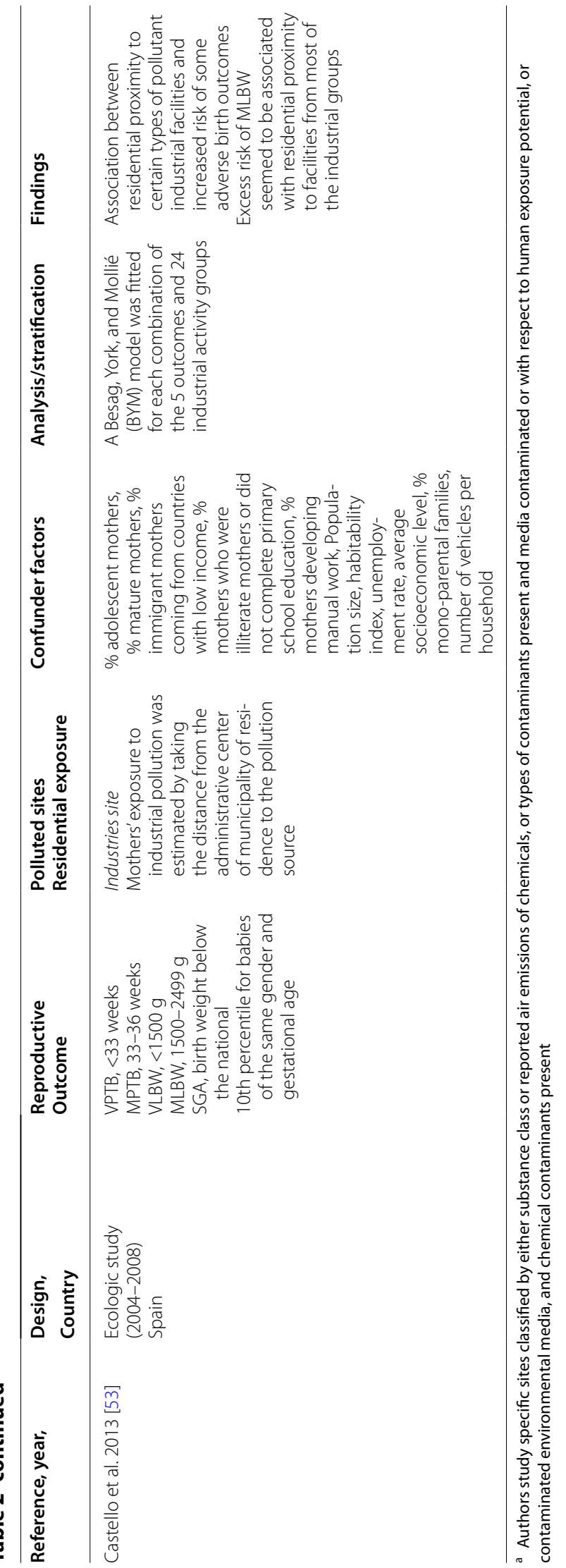




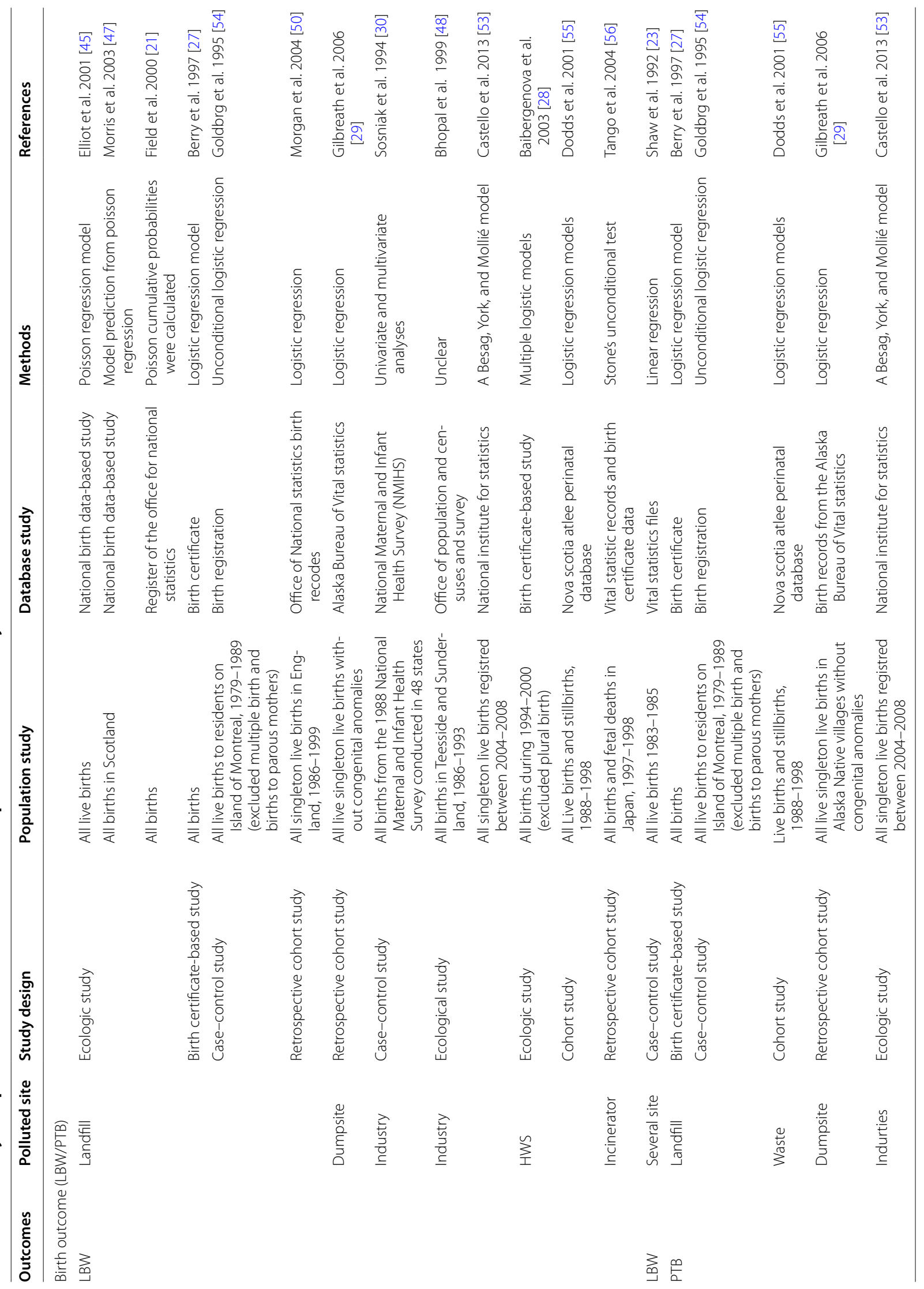




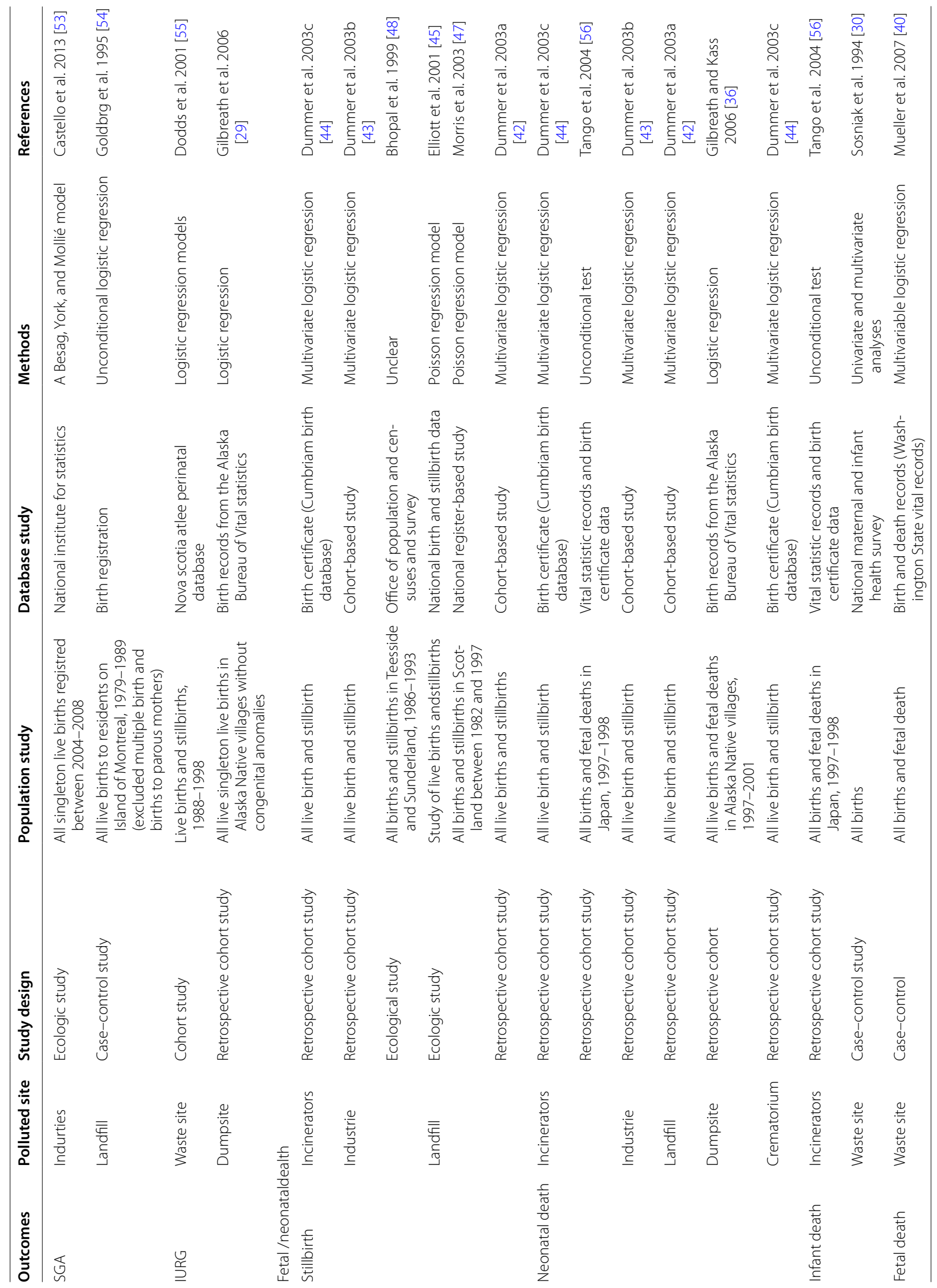




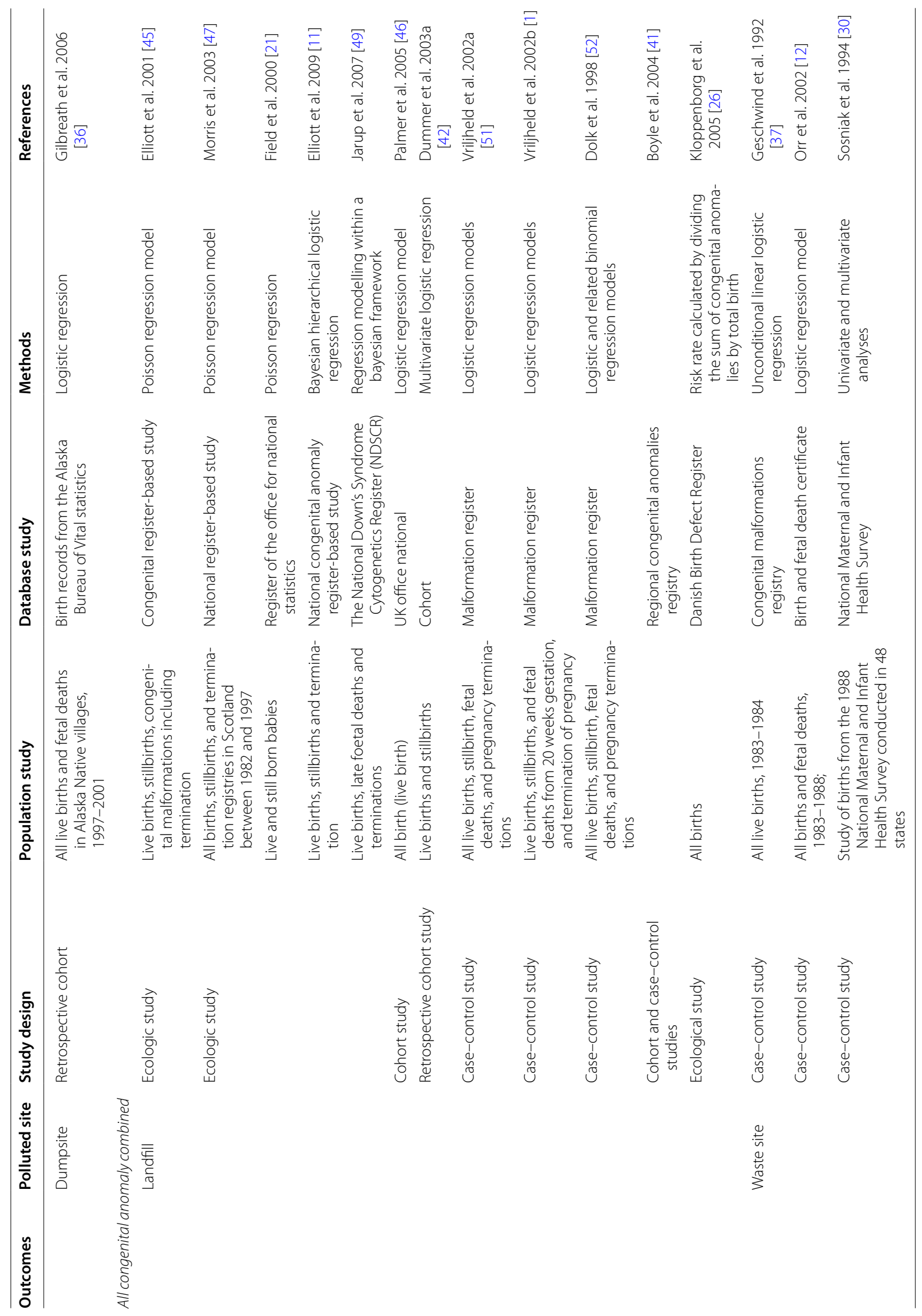




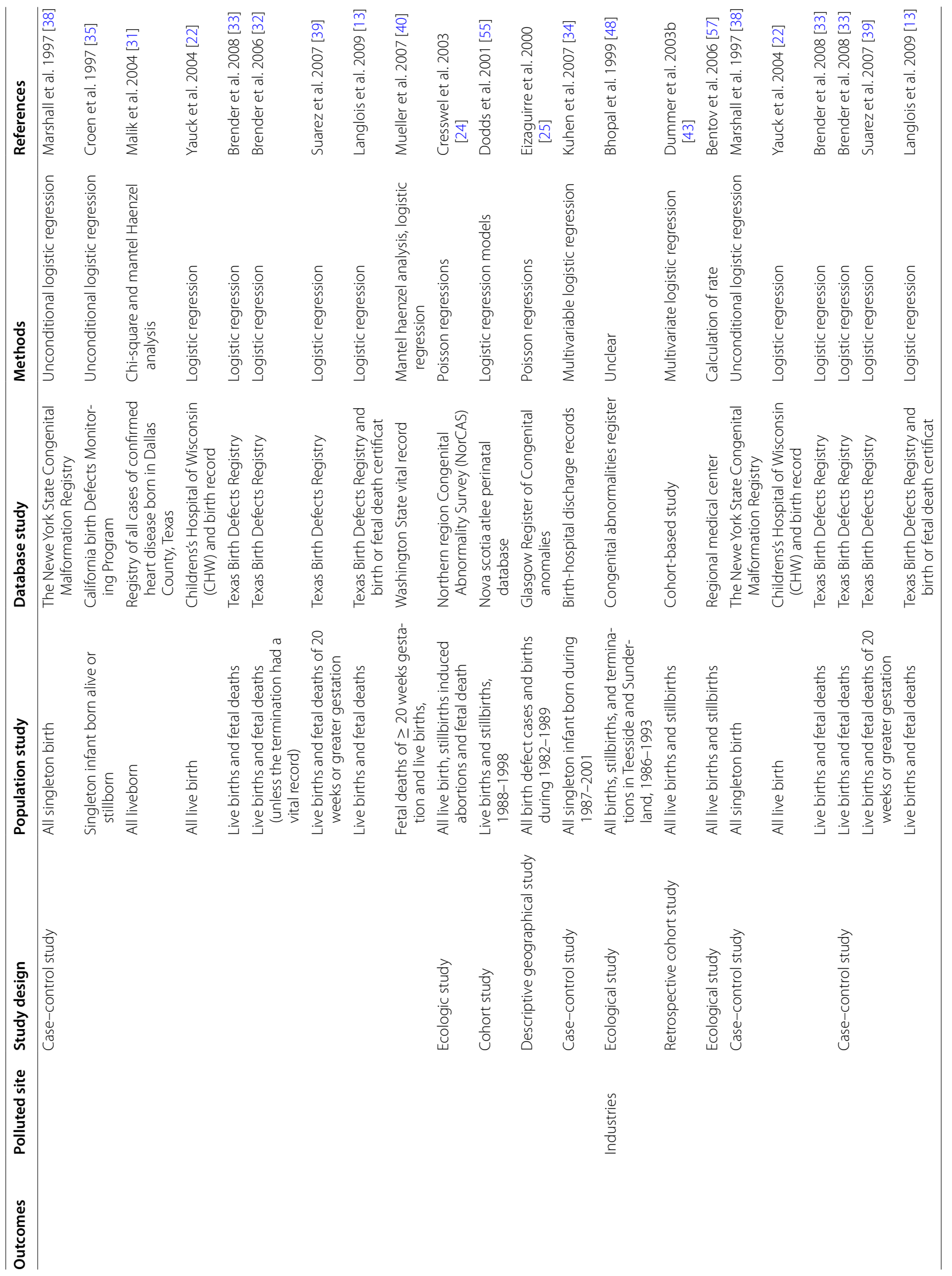




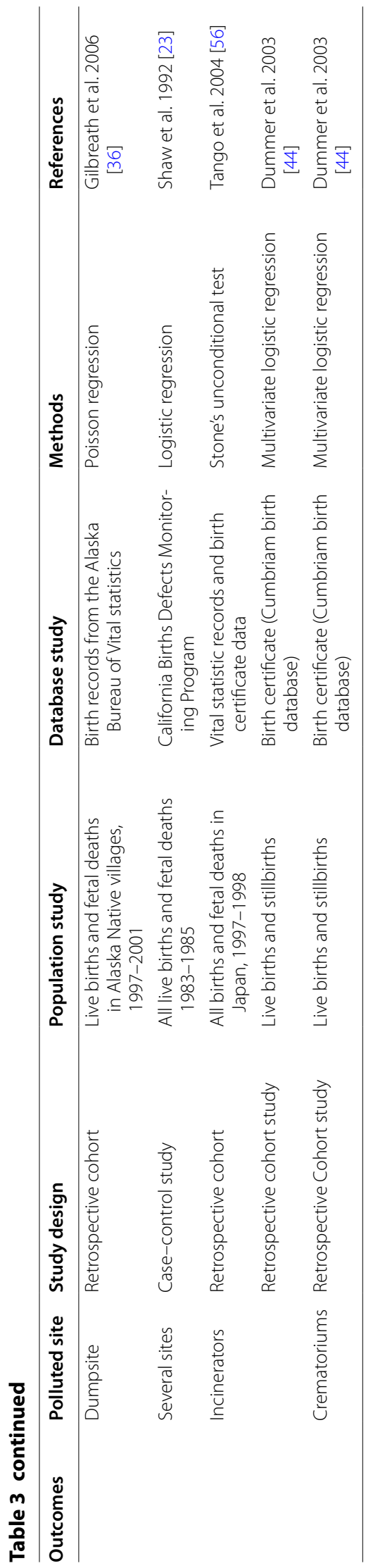




\section{Landfill sites}

One study considered all landfill sites located within the study area [41]. Three of the papers investigated a single landfill site [21, 27, 54]. European studies based on the EUROHAZCON method selected sites that contained hazardous waste of non-domestic origin, as defined in the EC directive on hazardous waste [1, 50-52]. Palmer et al. [46], explored landfills that were licensed for storage of chemical waste and those that subsequently introduced containment and/or gas venting. In the same year, in Denmark, Klopen et al. [26] focused only on deposit and regular landfills which might have contaminated water and/or air, and which had been operating for more than 7 years prior to the start of their study.

Three studies [11, 45, 49] used the UK practice of co-disposal of special and non-special waste, and classified the waste by type that was handled and whether sites were licensed to store special hazardous waste (special/non-special, unknown). Special landfill sites are designed for co-disposal of hazardous, biodegradable and inert waste, whereas non-special landfill sites are designed for biodegradable and inert waste only (non-hazardous). On the basis of this classification, in 2003 Morris et al. studied the reproductive impact of residential proximity to special waste only [47]. Other studies used a more specific classification. Based on site files and Environment Agency classifications, Dummer et al. [42], assigned a code to each site that described the waste types treated, in order to rank them from lowest to highest potential toxicity: Type 1: inert, Type 2: nonhazardous, Type 3: household/putrescible, Type 4: difficult-to-handle [42]. Vrijheid et al. [1] used an expert panel scoring guide to obtain the hazard potential of a landfill site.

\section{Hazardous waste sites (HWS)}

Most studies relating to HWS have considered all categories of sites-with the exception of three, which explored: the reproductive impact of proximity to specific waste sites such as waste sites contaminated by polychlorinated biphenyl (PCB) [28] or those emitting TCE (trichloroethylene) [22]; one area polluted by chromium [25] and the Byker waste combustion plant [24].

Several studies exploring HWS employed the dedicated US-Environmental Protection Agency classification. Using the National Priority List (NPL) sites, including: inactive pesticide and chemical manufacturing plants, wood treatment and preserving facilities, drum storage facilities, mines, contaminated groundwater areas, sanitary landfills, and military bases), the authors studied any polluted site versus NPL-sites, non NPL-sites [13, 32, 33,39 ] or all HWS versus HWS placed on a Superfund list (deemed higher-risk) [31]. Moreover, based on data characterizing the release of hazardous substances, the authors classified each hazardous waste site (both NPL and state Superfund sites) according to the environmental media contaminated and the specific chemical contaminants present-whether soil, surface water or air-were reported to be contaminated with heavy metals, PAHs or solvents [13, 32, 33, 35, 38, 39]. Also based on this US classification, Two other studies investigated residential proximity to NPL-sites $[12,30]$ and categorized NPL sites by those hazardous substances most present [12].

Another HWS classification was used by Mueller et al. [40] and Kuehn et al. [34] based on the hazardous potency of each site. Using the Washington Ranking Model (WARM), each site was rated on a scale ranging from of 1 ('high-priority' waste site) to 5 ('low-priority' waste site). Mueller et al. [40] also classified according to type of hazardous substance (solvents, metals, pesticides, radioactive substances) and contaminated media (water, drinking water, soil and sediment, air).

\section{Industrial sites}

Studies concerning industrial sites considered either any, or specific, industrial sites. Only two papers investigated a specific petrochemical industry [48], TCE emitting industry [22], or regional industrial park compound of 17 facilities [57]. Five US studies explored the health effects of all facilities taken together regardless of characteristics, or facilities classified according to their air releases, using information from the EPA Toxic Release Inventory. More precisely, the authors classified each industry by sector (petroleum refinery, primary metals or chemical industry) and by whether heavy metals or solvents were released [13, 32, 33, 38, 39]. Conversely, given that no specific data on emissions from hazardous industrial facilities is available in England, Dummer et al. [43] included all industrial sites that handled hazardous materials and chemicals, defined according to the Environment Agency register [43]. Lastly, in a recent European study, Castelló et al. [53]. investigated several types of industries - both as a whole and separately [53].

\section{Incinerators}

For this source, although the British study explored proximity to all incinerators [44], the Japanese one investigated only those incinerators having dioxin emission levels of above $80 \mathrm{ng} \mathrm{TEQ} / \mathrm{m}^{3}$ [56].

\section{Confounding}

Most studies adjusted for parental characteristics (e.g. maternal age, education, and marital status), birth 
Table 4 Summary of GIS-based (geographic information system) approaches used to assessed residential proximity to polluted site

\begin{tabular}{|c|c|c|c|c|c|}
\hline Approach & Polluted sites & Study design & Exposure threshold & Study location & Auteurs, year \\
\hline \multirow[t]{24}{*}{ Distance-decay modeling } & TRI & Case-control & 0.5 mile & Texas & Suarez et al. 2007 [39] \\
\hline & & & 1.6 km (1 mile) & Texas & Langlois et al. 2009 [13] \\
\hline & & & & Texas & Brender et al. 2008 [33] \\
\hline & & & & Texas & Brender et al. 2006 [32] \\
\hline & & & & Texas & Suarez et al. 2007 [39] \\
\hline & & & 3.5 km (or 2 miles) & Texas & Suarez et al. 2007 [39] \\
\hline & & & 4.8 km (3 miles) & Texas & Suarez et al. 2007 [39] \\
\hline & & Cohort & Continuous measure & England & Dummer et al. 2003b [43] \\
\hline & & Ecological & 3.5 km (or 2 miles) & Spain & Castello et al. 2013 [53] \\
\hline & Waste site & Case-control & 1.6 km (1 mile) & California & Croen et al. 1997 [35] \\
\hline & & & & California and New York & Sosniak et al. 1994 [30] \\
\hline & & & & Texas & Suarez et al. 2007 [39] \\
\hline & & & & Texas & Malik et al. 2004 [31] \\
\hline & & & & Texas & Brender et al. 2008 [33] \\
\hline & & & & Texas & Brender et al. 2006 [32] \\
\hline & & & & Texas & Langlois et al. 2009 [13] \\
\hline & & & 8 km (5 miles) & Washington state & Mueller et al. 2007 [40] \\
\hline & & & & Washington state & Kuehn et al. 2007 [34] \\
\hline & & & Pondered distance & New York & Geschwind et al. 1992 [37] \\
\hline & Landfill & Case-control & Continuous measure & 5 pays européens & Vriljheld et al. 2002a [51] \\
\hline & & & $2 \mathrm{~km}$ & Wales & Palmer et al. 2005 [46] \\
\hline & & Cohort & Continuous measure & England & Dummer et al. 2003c [42] \\
\hline & Incinerator & Cohort & Continuous measure & England & Dummer et al. 2003a [44] \\
\hline & Crematoriums & Cohort & Continuous measure & England & Dummer et al. 2003 [44] \\
\hline \multirow[t]{17}{*}{ Buffer-based approach } & Waste site & Case-control & 1.6 km (1 mile, 1.32) & New York State & Marshall et al. 1997 [38] \\
\hline & & & & Milwaukee, Wisconsin & Yauck et al. 2004 [22] \\
\hline & & Ecological & $3 \mathrm{~km}$ & New Castle upon Tyne & Cresswell et al. 2003 [24] \\
\hline & & & $\begin{array}{l}\text { A10 km subdivided into one } \\
\text { circle of } 2 \mathrm{~km} \text { and } 1 \mathrm{~km}\end{array}$ & Glasgow and nearby areas & $\begin{array}{l}\text { Eizaguirre-García et al. } 2000 \\
\text { [25] }\end{array}$ \\
\hline & Landfill & Ecological & $2 \mathrm{~km}$ & Great-britain & Elliott et al. 2001 [45] \\
\hline & & & & Scotland & Morris et al. 2003 [47] \\
\hline & & & & England and Wales & Jarup et al. 2007 [49] \\
\hline & & & & Denmark & Kloppenborg et al. 2005 [26] \\
\hline & & & Exposure index-2 km & Great-britain & Elliott et al. 2009 [11] \\
\hline & & & $3 \mathrm{~km}$ & South Wales & Fielder et al. 2000 [21] \\
\hline & & Case-control & $3 \mathrm{~km}$ & 5 pays européens & Vriljheld et al. 2002a [51] \\
\hline & & & & 5 pays européens & Vriljheld et al. 2002b [1] \\
\hline & & & & Europe & Dolk et al. 1998 [52] \\
\hline & & & $2-3$ versus $4-5 \mathrm{~km}$ & Dublin, kildene, Wicklow & Boyle et al. 2004 [41] \\
\hline & & Cohort & $3 \mathrm{~km}$ & England & Morgan et al. 2004 [50] \\
\hline & Industry & Ecological & $20 \mathrm{~km}$ & Beer-Sheva subdistrict & Bentov et al. 2006 [57] \\
\hline & Incinerator & Cohort & $2 \mathrm{~km}$ & Japan & Tango et al. 2004 [56] \\
\hline \multirow[t]{3}{*}{ Neighbor-based approach } & Landfill & Ecological & NR & Philadelphia & Berry et al. 1997 [27] \\
\hline & & Case-control & NR & Montreal & Goldberg et al. 1995 [54] \\
\hline & Industry & Ecological & NR & United Kingdom & Bhopal et al. 1999 [48] \\
\hline
\end{tabular}


Table 4 continued

\begin{tabular}{|c|c|c|c|c|c|}
\hline Approach & Polluted sites & Study design & Exposure threshold & Study location & Auteurs, year \\
\hline \multirow[t]{6}{*}{ Spatial coincidence } & Waste site & Ecological & Zip-code & New York State & Baibergenova et al. 2003 [28] \\
\hline & & Case-control & Census tracts & California & Orr et al. 2002 [12] \\
\hline & & & & California & Croen et al. 1997 [35] \\
\hline & & & & San Francisco Bay Area & Shaw et al. 1992 [23] \\
\hline & & Cohort & City & Sydney, Nova Scotia & Dodds et al. 2001 [55] \\
\hline & Dumpsites & Cohort & Villages & Alaska & $\begin{array}{l}\text { Gilbreath et al. 2005a, b } \\
{[29,36]}\end{array}$ \\
\hline
\end{tabular}

TRI Toxic Release Inventory facilities

characteristics (e.g. parity, number of previous stillbirths, gender of baby, gravidity, prior fetal death, etc.) and unhealthy practices (maternal smoking and alcohol consumption during pregnancy). Because of the lack of available information on dietary factors (such as folic acid supplementation, folic acid and vitamin intake during pregnancy), few studies have adjusted risk estimates for these variables. Some authors did take account of other confounders; a few studies adjusted for other exposure sources, such as parental occupation with relevant exposures (e.g. exposure to solvents or metals), or neighborhood characteristics (census tract median income, population density, urban versus rural residence, neighborhood socio-economic status).

\section{Methodology for spatial definition of residential proximity to polluted sites}

The choice of GIS approach differs between studies according to the type of polluted sites (HWS, landfill, or industrial site) and the study design which was conducted.

\section{GIS-based approach}

We identified four main GIS-based approaches used to delineate population at risk close to polluted sites: (i) the approach based on distance-decay modeling, (ii) the buffer-based approach, (iii) the spatial coincidence method and (vi) the neighbor-based approach (see Table 4).

\section{Potential exposure of a population living close to hazardous industrial facilities}

The main method used to estimate the potential exposure of a population living close to hazardous industrial facilities was based on distance-decay modeling method $[13,32,33,39,43,53]$ with the exception of one study based that used buffer method [57] and another neighbhorhood-based approach [48].
The authors used GIS tools to measure the straightline distance between the location of the study population and the nearest polluted site. Depending on data availability, the location of the population was based either on individual data (mother's residence [13, 32, $33,39]$ ) or on data aggregated across geographic units such as postcodes [53]. Some studies have extended this general concept to compute individual proximity measures. For example, Dummer et al. [43] conducted an individual study whereby for each birth, an individual proximity measure, $\lambda$, was calculated using the following formula,

$$
\lambda=\frac{1}{(\mathrm{D}+0.1)^{2}}
$$

where $\mathrm{D}$ is the distance from polluted site to mother's residence. The measure was summed over all sites in operation, covering the study territory at birthdate.

More recently, Castelo et al. [53]. estimated maternal exposure to industrial pollution by taking into account the distance from the administrative center of the residential municipality to the pollution source, using a purpose-designed distance matrix between all industrial installations and all municipalities.

Moreover, to investigate proximity to industrial site, Bentov et al. constructed a buffer to delineate the zone at risk for each industrial sites [57], while Bhopal et al. [48], aggregated several neighborhoods into 3 zones (A, B, and $\mathrm{C}$-with $\mathrm{A}$ being closest to industry and $\mathrm{C}$ most distant). They did not, however, explain their criteria used to define each zone.

Potential exposure of a population living close to landfill sites The main method used to estimate the potential exposure of a population living close to landfill sites was based on buffer method [1, 11, 21, 27, 41, 45, 47, 49-52] with the exception of three studies based on Distance-Decay Modeling Method [42, 46, 51] and two others based on neighborhood-based approach $[27,54]$. 
For instance, to investigate proximity to a landfill site, a circle of predefined radius is drawn around the polluted site. Some studies have extended this simple concept to calculate a landfill exposure index. Elliot et al. [11] addressed the issue of multiple exposures, exploring variation in risk of congenital abnormalities among areas hosting differing geographic landfill site densities by calculating an index based on the number of hazard zones (using a $2 \mathrm{~km}$ radius circle around each landfill site) overlapping each postcode. The resulting number was then related to birth data, and aggregated over a $5 \times 5 \mathrm{~km}$ grid [11].

In some European studies based on the EUROHAZCON approach, and in one US study, an area of $7 \mathrm{~km}$ radius around each landfill defined a 'study area'. Each study area contained a 'proximate' zone of $3 \mathrm{~km}$ radius from the site, within which the population was considered to be most exposed to chemical contaminants. This was compared to the 'unexposed' population within 'distal' zones of 3-7 km [1, 47, 50-52].

In 1995, Goldberg et al. [54] defined a set of three putative exposure zones representing proximal and distal areas to a municipal solid waste landfill site. These zones were formed by grouping contiguous or near-contiguous postal code areas. The high exposure zone consisted of the postal code area in which the waste landfill site was located, or which bordered it. In another US study conducted in 1999, Berry et al. defined exposed mothers as those living closest to the Lipari landfill in the only neighborhood next to the landfill [27].

\section{Potential exposure of a population living close to hazard waste site}

The main method used to estimate the potential exposure of a population living close to hazardous HWS was based on Distance-Decay Modeling Method [13, 30-35, $37,39,40$ ] followed by five others studies based on buffer method [22, 24-26, 38] and five others based on spatial coincidence method [12, 23, 28, 35, 55].

To measure the proximity to HWS using the straightline distance, the location of the population was based either on individual data (mother's residence [13, 31-35, $37,39,40]$ ) or on data aggregated across geographic units such as zip code centroids or postcodes [30].

In 1992, Geschwind et al. created an individual 'exposure risk index' incorporating distance from, and the hazard raking score, for each site within a 1-mile radius of birth residence [37]. Thus, the higher the waste site score and the closer an individual's proximity to a site, the greater the weighting factor assigned.

Some authors entails constructing a buffer to delineate the zone and population at risk for each HWS (see above in "Potential exposure of a population living close to hazardous industrial facilities" section) to compare to the 'exposed' population in 'proximate' zone with 'unexposed' in 'distal' zones [22, 24, 25, 38].

While, Croen et al. [35] defined a measure of proximity as one indicating whether the census tract of residence contained a waste site. Baibergenova et al. [28] defined exposed groups as those residing in a zip code hosting PCB-contaminated sites, and unexposed groups as residing in zip codes not hosting PCB-contaminated sites. Orr et al. [12] considered that where a census tract contained one or more NPL sites, the children born in that census tract were considered to be 'potentially exposed'. These studies used a variety of spatial units with different resolution scale (zip code, census block) [12, 28, 35].

\section{Potential exposure of a population living close to specific hazard waste site}

Among studies focusing on excess risk of pregnancy outcome associated with living near specific HWS, different method used to estimate the potential exposure of a population living close to specific HWS (including incinerator $[44,56]$, dumpsite $[29,36]$ and crematoriums [44]) was based on Distance-Decay Modeling Method [44], buffer method [56] and spatial coincidence [29, 36].

Some studies have extended a general concept to examine the relationship between reproductive outcome and nuisance intensity, measured by the amount of chemical released or by the toxic potency of the chemicals. For example, several authors $[29,36]$ investigated whether women living in villages having 'highly hazardous' open dumpsites had greater rates of adverse pregnancy outcome than women living in villages with sites having a lower hazard ranking.

\section{GIS-based approach according the study design}

Except one ecological study [53], all studies which used distance-decay modeling method to estimate the potential exposure of a population living close to polluted site were individual studies including mainly case-control [13, 30-35, 37, 39, 40, 51] and also four cohort studies $[42-44,46]$.

Most ecological studies including one descriptive geographic study [11, 21, 24-26, 45, 47, 49, 57] and several case-control studies [1, 22, 38, 41, 51, 52] used buffer method to investigate the excess risk of pregnancy outcome associated with living near polluted sites, while only three cohort studies $[50,56]$ used this method to estimate the potential exposure of a population living close to polluted sites.

Similarly, while no cohort study used neighborhood based approach, two ecological $[27,48]$ and one case-control study [54] used this approach to estimate the potential exposure of a population living close to polluted sites. 


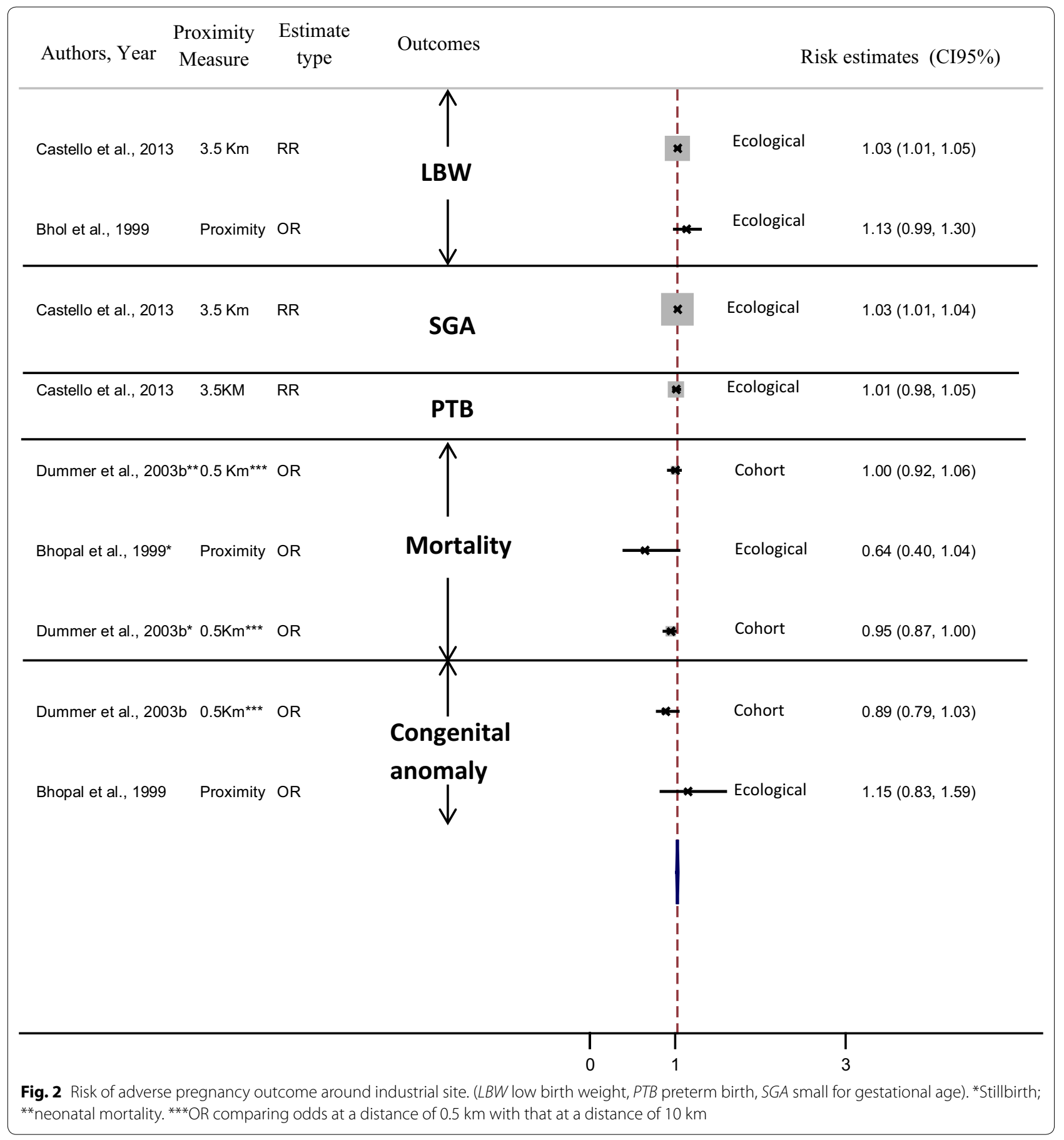

In contrast, among few studies which used spatial coincidence method, the most studies were individual including three cohort studies [29, 36, 55] and three case-control studies [12, 23, 35], and only one ecological study [28] used this approach to estimate the potential exposure of a population living close to polluted sites.

\section{Exposure threshold}

The definition of residential exposure zone differs between studies according to the type of polluted sites (HWS, landfill, or industrial site) and the country in which the study was conducted.

In most US studies, exposed women were located within either 1 mile of waste sites [13, 22, 23, 30-33, 35, 


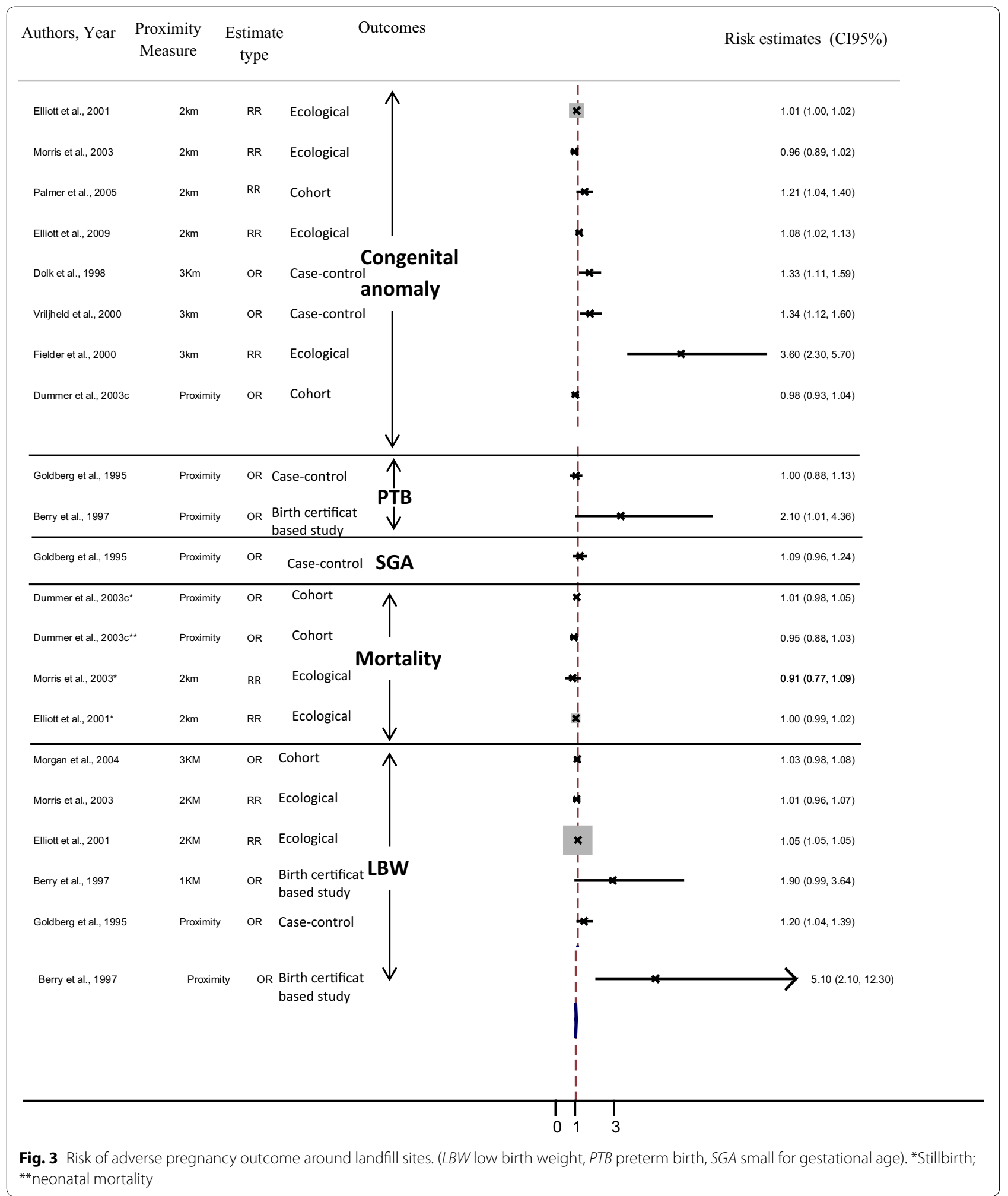

39] or 5 miles [34, 40], though distances of $3 \mathrm{~km} \mathrm{[24]}$ or $2 \mathrm{~km}$ [25] from waste sites or specific HWS were also found. In a few European studies and one other
US study, exposed women were those who lived within either 3 miles [38, 53] or 1 mile of industrial sites [13, 32, 33, 39]. Most analyses based on buffer methods 


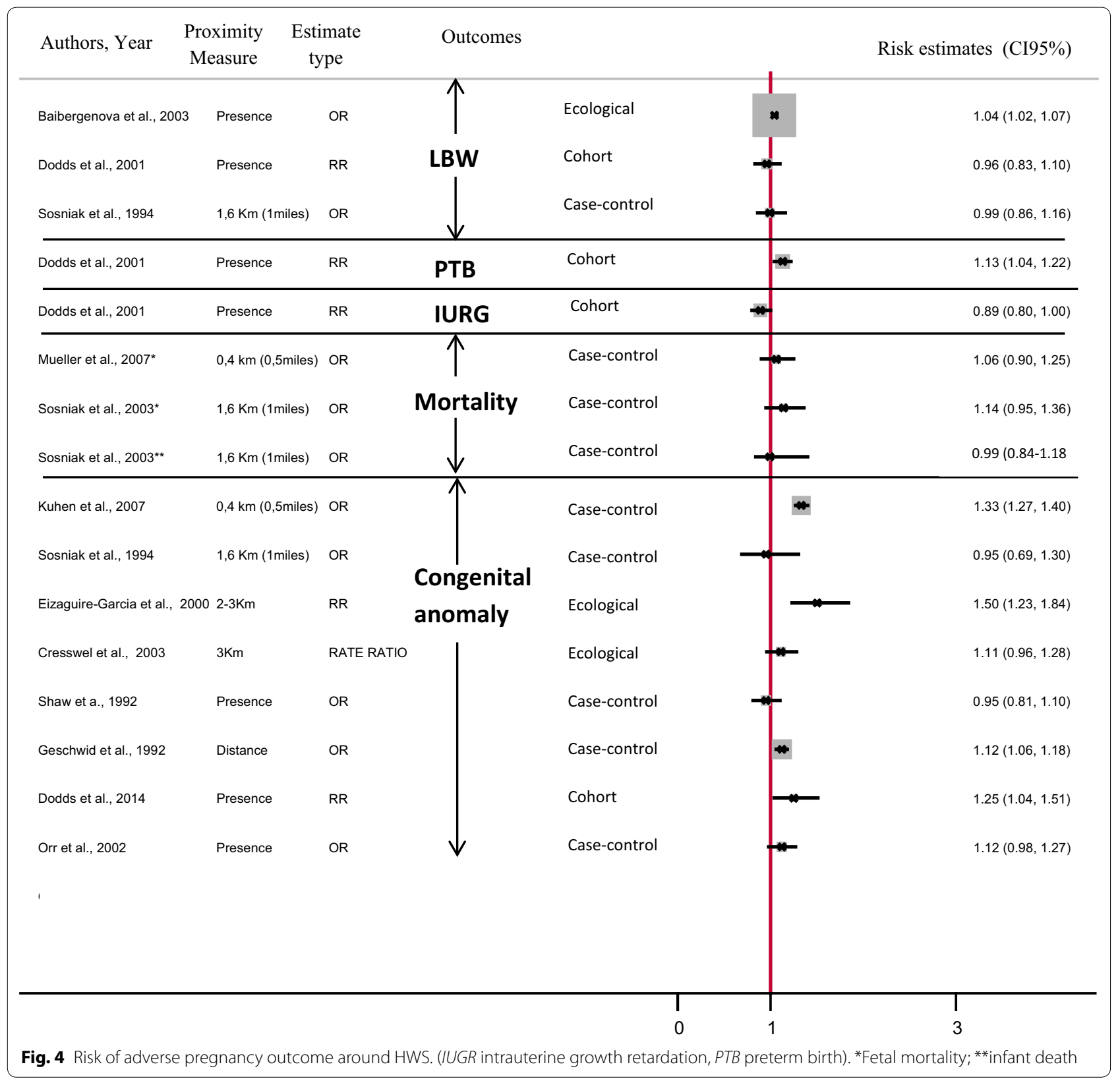

defined areas of $1 \mathrm{~km}$ [27], $2 \mathrm{~km}[11,26,45,47,49]$ or $3 \mathrm{~km}[1,21,51,52]$ radius around each landfill site as being 'zone-proximate' and thus classified as 'exposed'.

\section{Overview of current evidence concerning possible effects on pregnancy outcome of proximity to polluted sites}

In this section, the results of studies are structured by type of polluted site, namely (i) industrial site (ii) HWS, (iii) Landfill site and (vi) incinerator/dumpsite.
Risk of adverse pregnancy outcome around industrial site:

(Fig. 2)

Among studies focusing on excess risk of pregnancy outcome associated with living near industrial facilities, results show that the risk of PTB or very PTB [53] stillbirth [43, 48] and neonatal death [43] were not found to be associated with living in close proximity to specific industries $[43,48]$. However, other studies show an increase in the prevalence of LBW and MLBW, as well as risk of SGA, with residential proximity to industrial facilities from different sectors of 


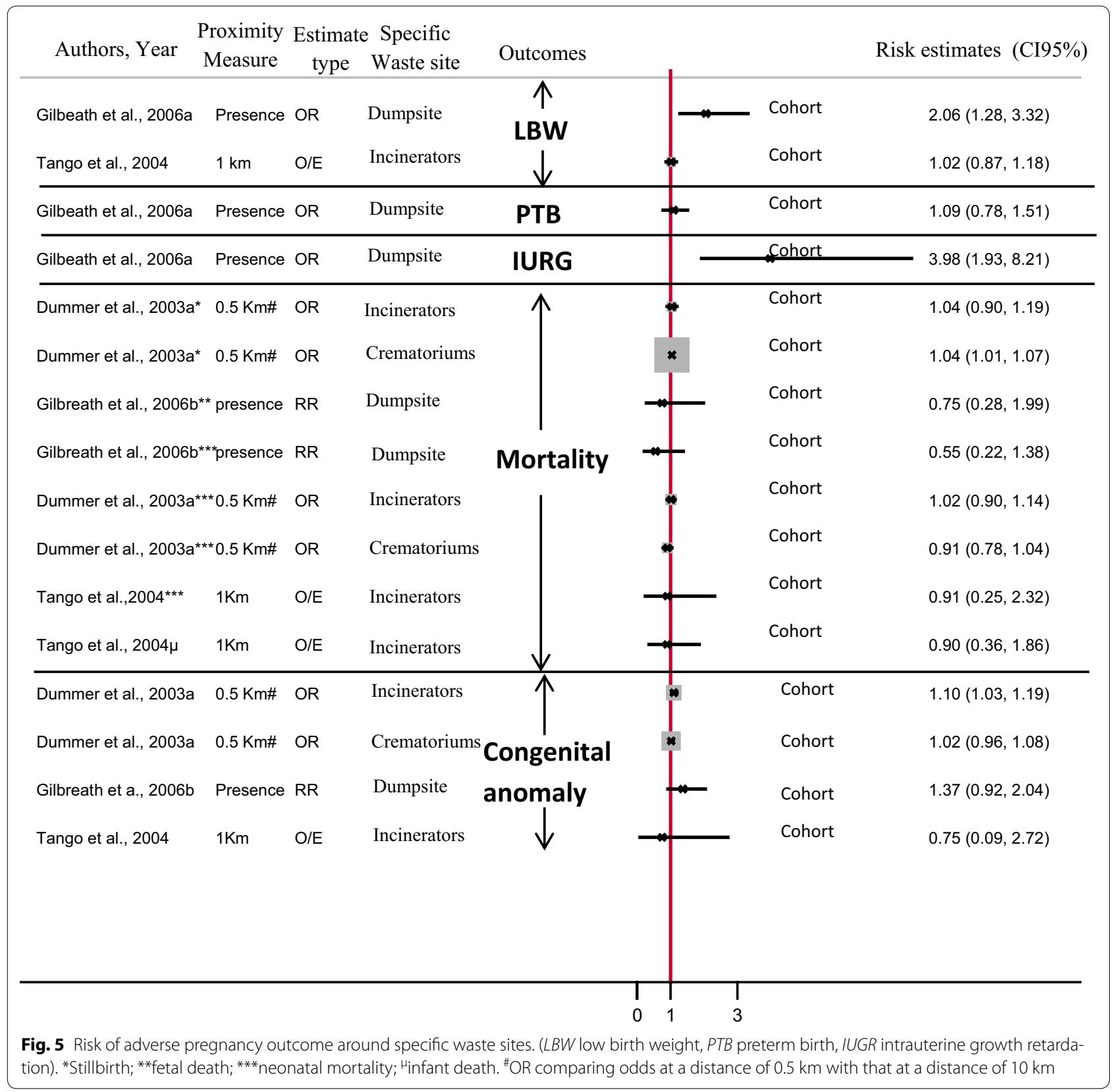

activity $(\mathrm{RR}=1.03 ; 1.01-1.05$ [53]; OR $=1.13(0.99-1.30)$ [48]; $R R=1.03 ; 1.01-1.05$ [53] respectively).

In addition, with the exception of two studies which reported no association between proximity to industrial sites and all congenital anomalies combined [43, 48], our review reveals that women living close to industrial sites have an increased risk of giving birth to children with:

- overall congenital malformations $(\mathrm{RR}=1.17 ; 1.04-$ 1.29-among Bedouin populations-[57]),

- chromosomal abnormalities (OR $=4.8 ; 1.2-42.8$ only among women aged 40+ [33]),
- specific congenital malformations including neural tube defects (OR $=1.2 ; 1.0,1.5$ [39]) and Congenital Heart defects (CHD) $(\mathrm{OR}=3.2 ; 1.2-8.7$ [22] with proximity to trichloroethylene-emitting sites,

- increased risk of death from congenital heart defects $(\mathrm{OR}=1.06 ; 1.02-1.10$ in $1983-1993$ [43].

\section{Risk of adverse pregnancy outcome around landfill sites:}

(Fig. 3)

Among studies focusing on the relationship between pregnancy outcome risk and residence near landfill, the results reveal that the risk of mortality including: 
stillbirth [42, 45, 47], spontaneous abortion [21], neonatal death [42] and SGA [54] was not found to be associated with living in close proximity to landfill $[45,54]$ or specific landfill [21, 42, 45, 47].

However, an increase in the prevalence of very LBW [45], LBW and risk of PTB with residential proximity to landfills $(\mathrm{RR}=1.04 ; 1.03-1.05)$ [45]; $\mathrm{RR}=1.05 ; 1.05-1.06$ [45]; $\mathrm{OR}=5.1 ; 2.1-12.3$ [27]; $\mathrm{OR}=1.20 ; 1.20-1.39$ [54]; $\mathrm{OR}=2.10 ; 1.01-4.36$ ) [27] respectively) were revealed by three studies-even though three other studies indicate that no statistically significant excess risks of LBW and PTB or very PTB [54] were detected in populations living near landfill [21, 47, 50, 54].

In addition, an increased risk of congenital abnormalities was found in the children of mothers living near:

- waste landfill ( $\mathrm{RR}=1.01 ; 1.01-1.02$ [45]; $\mathrm{OR}=1.33$; 1.11-1.59 [1]; $R R=1.9 ; 1.3-2.85$; before versus after opening $R R=1.9 ; 1.23-2.95$ [21] and $R R=3.6$; $2.3-$ 5.7 when site being developed and first used [21],

- special waste landfill ( $R R=1.07 ; 1.04-1.09)$ [45]; $\mathrm{OR}=1.08 ; 1.02-1.13$ [11]),

- landfill with chemical waste $(\mathrm{OR}=1.21 ; 1.04-$ 1.40) [46] or waste of medium hazardous category $(\mathrm{OR}=1.48 ; 1.19-1.85)[1]$, non domestic hazardous waste $(\mathrm{OR}=1.33$; 1.11-1.59) [52].

- non-domestic waste landfill $(\mathrm{OR}=1.41 ; 1.00-1.99$ for chromosomal abnormalities [51],

Moreover, studies reveal that women living close to a landfill site had:

- an increased risk of giving birth to children with specific congenital malformations including neural tube defects $(\mathrm{OR}=1.86 ; 1.24-2.79$ [52]; $\mathrm{RR}=1.05$; 1.01-1.10 [45]), cardiovascular defects $\mathrm{OR}=1.16$; 1.01-1.33 [11]); anomalies of great arteries and veins $\mathrm{OR}=1.81 ; 1.02-3.20$ [52] or cardiac septa $\mathrm{OR}=1.49 ; 1.09-2.04)[52]$,

- increased risk of death from 'other congenital abnormalities of the nervous system' closer to domestic waste landfill sites (continuous $\mathrm{OR}=1.14 ; 1.03-1.25$ for increasing proximity to landfill sites [42]).

However, three studies reported that no statistically significant excess risks of congenital abnormalities were detected in populations living around landfill sites [26, $41,47]$.

\section{Risk of adverse pregnancy outcome around hazard waste sites: (Fig. 4)}

Among studies focusing on relation between maternal residential proximity to HWS and adverse pregnancy outcome, results show that the risk of PTB was significantly elevated among infants born to women living near HWS (RR $=1.13 ; 1.04-1.22$ ) [55], but the risks of infant death [30], fetal death [40] and risks of low [30], very low birth weight [30] and IURG [55] were not found to be associated with living in close proximity to HWS [30, 40, 55] or NPL HWS [30].

Among studies focusing on specific sites, studies showed an excess risk of LBW with proximity to PCBcontaminated waste sites $(\mathrm{OR}=1.04 ; 1.02-1.07)$ [28] and higher risk of fetal death among women residing close to pesticide-containing sites $(\mathrm{OR}=1.28 ; 1.13-1.46)$ [40].

In addition, authors found a significant increase in the risk of congenital malformations among women living close to HWS (OR $=1.12$; $1.06-1.18$ [37]; OR = 1.15; $1.10-1.21$ [34]; $R R=1.25 ; 1.04-1.51$ [55]), with the exception of one; Sosniak et al. found that maternal residential proximity to NPL sites was not associated with adverse pregnancy outcome including: congenital abnormalities [30].

Moreover, authors revealed that an increased risk of congenital malformations was found only with proximity to specific waste sites including:

- waste sites emitting substances with specific biological effects (cytochrome oxidase inhibitors) $(\mathrm{OR}=1.3 ; 1.02-1.67)$ [12],

- chromium waste ( $R R=1.52 ; 1.24-1.85)$ [25],

- waste sites classified as 'high priority' $(\mathrm{OR}=1.16$; 1.11-1.20) [34].

Moreover, women living close to HWS had an increased risk of giving birth to children with specific congenital malformations including neural tube defects $(R R=1.83 ; 1.08-3.09$ [55]), and cardiovascular defects $(\mathrm{OR}=1.20 ; 1.1-1.4$ [31]; $\mathrm{OR}=4.99 ; 1.26,14.51$ [13]).

\section{Risk of adverse pregnancy outcome around specific waste sites: (Fig. 5)}

Among the studies focusing on the relationship between maternal residential proximity to specific waste sites and adverse pregnancy outcome, results reveal that risks of mortality including: stillbirth [44], neonatal death [44, 56] and infant death [56], and risk of LBW [56], were not found to be associated with living in close proximity to polluted incinerators [44] and specific incinerators [56] and crematoriums [44]). However, Dummer et al. [44] described a higher risk of stillbirth among residents $(\mathrm{OR}=1.04 ; 1.0 .1-1.07)$.

Dummer et al. also found a significant increase in the risk of lethal congenital malformations $(\mathrm{OR}=1.10 ; 1.03-1.19)$ [44], lethal specific congenital abnormalities including neural tube defects $(\mathrm{OR}=1.13 ; 1.04-1.23)[44]$ and heart 
defects $(\mathrm{OR}=1.12$; 1.03-1.22) [44] among women living close to incinerators but not around crematoriums [44].

Whereas in 2006 Gilbreath et al. revealed increased risk of IUGR and prevalence of LBW around the dumpsite $(\mathrm{OR}=3.98 ; 1.93-8.21$; $\mathrm{OR}=2.06 ; 1.28-3.32)$ [29] respectively), these same authors have shown that risk of PTB [29] or very PTB [29], risk of neonatal death [36], fetal death [36] and congenital anomalies [36] were not found to be associated with living in close proximity to dumpsites [29] or specific dumpsites [36].

\section{Discussion}

\section{Main findings}

Based on cohort and case-control studies, our systematic review has shown the strength of the association between adverse pregnancy outcome and maternal residential proximity to polluted sites to be highly variable. Increased risks for non-chromosomal abnormalities, chromosomal abnormalities, low birth weight and small for gestational age were noted in several U.S. and European studies among populations living close to hazardous waste sites-yet measures of association were not significant for other types of birth defects.

Our review mainly reveals an excess risk of reproductive morbidity-though not of mortality. Despite several nonsignificant associations, Fig. 2 shows that all published studies are on the side of an increased risk of congenital abnormalities. In addition, Fig. 2 shows that all but four studies exhibited an excess risk of low birth weight. Results for preterm birth [27, 29, 53-55], SGA [53, 54] and IUGR $[29,55]$ convey the same pattern (see Figs. 2, 3, 4, 5).

Our literature review highlights the fact that the differing findings of studies may, in part, be due to how 'proximity of residence' is assessed. For example, in a study involving five European countries and 23 hazardous waste landfill sites, women who lived within $3 \mathrm{~km}$ (1.9 miles) of such a site were 1.5 times (95\% CI 1.0-2.2) more at risk of chromosomal abnormalities than women living in the 3-7 km band [51]. On the other hand, in 2008 [33], Brender et al. found no association between living near hazardous waste sites and chromosomal abnormalities ( $\mathrm{OR}=0.90 ; 0.70-1.2)$. In a study among California residents of maternal residence near NPL waste sites and birth defects, women who lived in a census tract having one or more NPL sites were more likely to have births with congenital abnormalities (Patau syndrome or Edward's syndrome or other sex chromosome abnormalities $\mathrm{OR}=2.65 ; 1.37-5.13$; OR $=2.7 ; 1.53-$ $4.61 ; \mathrm{OR}=3.1 ; 1.01-9.62$, respectively) [12].

These contrasted results could be partially explained by methodological limitations inherent to (i) exposure assessment, (ii) the GIS methods, which could also affect the strength of association. In addition, several inaccuracies and biases, inherent to different analysis methods, may bias cross-study comparisons and conclusions drawn from them. These limitations will be discussed below in the second part.

\section{Exposure assessment}

The main limitation of the studies reviewed in the present paper lies in exposure assessment, which comprises (i) categorization of exposure sources and (ii) factors influencing the potential exposure to polluted sites.

\section{Categorization of exposure sources}

We sum up the four main methodological limitations regarding the categorization of exposure sources that may yield exposure misclassification.

Firstly, in some cases (such as practice of co-disposal in the UK) the two categories of special and non-special waste may not necessarily correspond to higher levels of hazard in the former, as has been hypothesized by some authors. The special waste sites may handle smaller volumes of hazardous waste and be subject to stricter management and design standards than other non-specialized waste sites, at which hazardous wastes may have been disposed of unreported.

Secondly, most US studies have included sites with 'unknown waste' in the analysis. The large number of such sites provides potential for uncertainty as to their degree of hazardousness. In practice, sites were likely to be of unknown type for three main reasons: (i) because they were legally not subject to regulation due to the nature of their operation (e.g., small dump sites in farms, taking agricultural waste from the holding), (ii) because they were not active during the study period, or (iii) because they were informal sites not identified by the competent authorities. Thirdly, with the exception of studies of special waste sites, most studies were based on polluted sites falling into more than one hazardous substances category-and in addition, some census tracts contained more than one site. In such instances, the association cannot be ascribed to a particular category of pollution or site [12].

Lastly, in situations where pollution remediation (or at least containment) may be in process, it is likely that exposures of neighboring residences have been reduced. This might explain those cases where no association was found between maternal residence and chromosomal abnormalities in offspring [32, 33].

\section{Factors influencing potential exposure to polluted sites: consideration of dispersion factors}

Residential exposure to site contaminants and industrial emissions also varies according to climatic and topographic characteristics such as prevailing wind speed, 
direction and temperature. Within the constraints of the available data-including lack of geological, meteorological, or water supply information-these conditions were rarely accommodated except for few studies [27, 54, 57]. Whatever the measure used by studies to estimate the potential exposure of a population living close to polluted sites including both buffer-based and distance-based approaches, the author not consider dispersion factorsthe reduction of personal exposure to a simple distance function is restrictive. Most other studies ignored this point; they considered emissions from a facility to be uniformly dispersed in all directions, and environmental exposure to be equally distributed around the polluted sites. Yet a resident who lives one mile upwind of a hazardous facility is unlikely to experience the same level of exposure as someone living one mile downwind. According to the study by Brender et al. [33], this point may particularly impact women living close to two or more facilities.

\section{GIS-based methodology}

Since use of GIS tools is now widespread, computing proximity-based indicators is fast, easy and applicable to large data sets. Basic GIS functions, such as point-in polygon, intersect, or buffering distance are used. Moreover, to assess polluted site exposure, GISbased approaches seem pertinent to explore "geophysical plausibility" - a new term coined and described by Nuckols et al. [58]. To use in the application of environmental science to exposure assessment for epidemiology, they suggest this axiom which would dictate that: "an association between a contaminant source and exposure to an organism or ecologic community cannot exist unless there is a plausible geophysical route of transport for the contaminant between the source and the receptor" [58].

However, these proximity indicators may bias assessment of residential exposure due to GIS-approach procedures used to define proximity to polluted sites. Studies using spatial coincidence methods are limited by their inability to consider the exact geographic location of the hazard within the host spatial unit and determine the geographic extent of exposure. In order to address the limitations of the spatial coincidence approach, most studies have analyzed residential proximity either on the basis of distance, or using the buffer method. Buffer methods and distance based-approach analysis provide more accurate and realistic estimates of exposure than spatial coincidence methods because they do not assume that adverse effects are restricted to the boundaries of the pre-defined analytical units hosting the hazard source. However, there are specific limitations associated with its application, with various sources of both error and uncertainty, i.e. (i) physical geography of the facility; (ii) definition of residential proximity: "Geophysical Plausibility".

\section{Physical geography of the facility}

Most studies have assumed that the facility or contamination site was small enough to be treated as a point source; few have considered their shape and size in deciding which type of buffer was appropriate [32, 33, 35]. Yet landfill sites vary greatly in terms of surface area, from $50 \mathrm{~m}^{2}$ to 70 million $\mathrm{m}^{2}$ (average $64,600 \mathrm{~m}^{2}$ in the study base) [49], and areas and locations do change over time as sites evolve. The use of a point location to define sites yields uncertainties. Some hazardous sites should be polygon-delineated, with the buffer should be constructed around this shape [59].

Moreover, the properties and quantities of hazardous substances stored or released at each facility have rarely been incorporated to the determination of buffer radii to reflect the spatial extent of environmental exposure. Nor are the operational parameters of emission releases (e.g. release height, exit velocity, exit temperature) considered in determining buffer size.

\section{Definition of residential proximity: "geophysical plausibility"}

Misclassification of exposure may also arise out of the variety of radii or distances used (1,2 or $3 \mathrm{~km})$ to define proximity to polluted sites. Our review highlights the fact that radii of the circular buffers and distances defining maternal exposure have been chosen arbitrarily. Few authors have justified their choices $[1,11,13,45,47,49$, $51,52]$. The conclusion from a WHO report [60] had guided several authors who stated in their paper that exposure from landfill sites is likely to be limited beyond $1 \mathrm{~km}$ from the site by the air pathway, and $2 \mathrm{~km}$ by the water pathway [11, 45, 49]. Other authors based their choice on expert judgment, positing that exposure to chemical contaminants would occur within a $3 \mathrm{~km}$ radius of landfill sites $[1,51,52]$. In order to be consistent with most American studies of waste sites or industrial facilities in relation to birth defects, several authors chose to use the same radius $[13,47]$.

Irrespective of buffer size, there is some intrinsic inaccuracy in drawing such exposure areas [42]. In the absence of finer resolution information, and because of the complex nature of sites such as landfills, use of distance bands smaller than $2 \mathrm{~km}$ or a continuous measure to examine proxy dose-response relationships would have been beyond the resolution of the data $[45,49]$. While arguing that it is not possible to detect directional patterns using concentric circles, Palmer et al. [46] supported the idea that the use of $2 \mathrm{~km}$ radii, as chosen by Elliott et al. [11, 45] was pragmatic, 
maximizing the power of comparisons while remaining within plausible estimates of the range of chemicals dispersed from a site. No sound evidence has yet been published to assess human exposure with distance from landfills in the United Kingdom, but expert opinion suggests that small particles from landfills may be detectable up to $3 \mathrm{~km}$ away [60]. Alternatives to using concentric circles could be explored, given that the distribution of increased risk is not uniform with distance [61].

However, as explained by Elliott et al., distance from the nearest landfill site may not be regarded as a meaningful proxy for exposure where postcodes have been used to define the location of birth outcomes and where point locations had to be used for estimation of polluted sites, particularly in rural areas $[11,45]$.

\section{Assessment of the relation between spatial proximity to polluted site and reproductive outcome}

Interpretation of our findings must consider weaknesses that could affect the strength of the associations, yield limitations in comparisons or impede the formulation of accurate conclusions. These weaknesses, discussed below, are inherent to (i) outcome data, including the definition and the selection of the case, (ii) study design, and (iii) assessment of the risk of pregnancy outcome around polluted sites. In addition, beyond these factors, the systematic review we conducted also faced some methodological limitations.

\section{Outcome data-case selection}

There are several ways in which outcome data can be a source of bias. Firstly, findings may be distorted by selection bias. Examples given by some authors are exclusion of pregnancies terminated prior to 20 weeks of gestational age $[12,13,39]$ and pregnancy terminations without vital records [33]. This tends to bias association estimates towards low values and might even-at the extreme-reverse the direction of the true association because those women less likely to terminate pregnancies in conjunction with less frequent usage of prenatal diagnosis, lack of access to safe delivery facilities (e.g., poor women), or cultural practices (e.g., Hispanic women) may also be more likely to live closer to industries and waste sites [13, 33, 39].

Similarly, the population source between studies differs, having a potential impact on association measures. Whereas some authors collected their data from population-based studies encompassing all live births, fetal deaths and other pregnancy terminations, others had information only on live births-thus restricting ascertainment of birth defects [34, 37, 38].
One source of such limitation lies in the databases. Using linked birth-hospital discharge data may reduce the likelihood of missing malformations, because it includes malformations identified throughout birth hospitalization, rather than only at birth. Malformations resulting in early fetal death or elected termination, if not included, may yield the same effect, so that risk estimates of CNS and chromosomal malformations, in particular, may be inaccurate.

Outcome definition is another source of uncertainty. Unlike low birth weight (weight $<2500 \mathrm{~g}$ ) and preterm birth ( $<37$ week), the definition of congenital malformation was heterogeneous across studies, rending comparisons difficult. Some studies have excluded non-lethal congenital abnormalities [42-44], whereas some included only live births with congenital malformations [22, 26, 31, $34,37,38,41,46]$ and others included both live birth and fetal death with birth defect [12, 24, 32, 33, 39, 57]. Broad groupings of malformations into all congenital abnormalities combined may also have hampered the ability to examine associations for specific malformation types by diluting relevant cases [34]. The loss of precision inherent to such a general classification scheme (e.g. malformations placed within the same classification grouping) reduces the likelihood of detecting an association between malformations and the study exposures [37].

\section{Study design}

The ecological studies are all published from the 2000s as the cohort studies. While, in this work, a majority of the studies were conducted in US, we count 9 ecological studies realized in Europe, and only 2 in US $[27,28]$, and one in Israel [57]. Similarly, only one of the cohort study was conducted in US [36] whereas a majority came from UK. We count 19 case-controls studies conducted between 1992 and 2009. Inversely to ecological and cases-controls studies, a huge majority of the cases-controls studies were conducted in US; only four studies in Europe [1, 41, 51, 52] and one in Canada [54].

The outcomes most frequently investigated in the ecological is not the congenital abnormalities (as we observed when considering overall studies) but the birth outcome such as LBW, preterm birth, etc; (seven over the eleven ecological studies) whereas the inverse situation was observed in the cases-controls studies with a majority of studies dealing with the congenital abnormalities-only one study investigated the LBW and preterm birth outcome [54], and another one the fetal death [40]; two last one included various outcomes as LBW, fetal and infant death and congenital anomalies [23, 30]. The cohort study design is the only one for which, many studies dealt with death event: Infant, neonatal, and fetal 
deaths besides congenital malformations and 'classical' birth outcomes as LBW or preterm birth.

The landfill is the polluted site most frequently investigated in the ecological and cohort studies whereas in the cases-controls studies the polluted sites of interest were the hazardous waste and industrial sites. We also highlighted that the Europe cases-controls studies investigated landfill polluted sites which is coherent with the ecological and cohort studies.

The study designs could impact the quality of each study included in the review and consequently make difficult the comparison between studies. In addition, the study may impact (i) the measure of women exposure and (ii) the risk estimate.

Study design and the measure of women exposure The different study designs present itself strengths and limitations to measure the proximity to polluted site according to the available data.

Ecological approach In the ecological studies, the authors do not measure the exposure at the individual level, thus their results depends on the scale of spatial unit in which the indicator of exposure was estimate.

When the place of residence of each case is no known, the individual approach is no possible, and an ecological study is recommended. However, misclassifications of exposure may result from the use of municipality [53], or zip code [28] to define the location of maternal residence. Postcodes provide only an approximate location of the residential place. With an average of about 12 households per postcode in urban areas with high population density [11], it corresponds to a very small area. In contrast, in remote rural areas, a single postcode may cover an area of $1 \mathrm{~km}^{2}$ or more. Thus, there is the possibility for systematic bias in the exposure estimates (with less precise estimates in rural areas). Adjustment for rurality was partially controlled for this problem in the 2009 study by Elliott et al. [11].

Moreover, in ecological study, for which residential places are not known with precision, the indicator chosen to estimate exposure level is the mean which ignore the variability of exposure within the census block scale or zip code. Therefore, in the ecological approach, all women living within a given spatial unit have an equal exposure level, this presumption is known as ecological fallacy.

For instance, when authors used spatial coincidence methods to measure of women exposure based on the presence of polluted sites within a particular spatial unit of aggregation, the authors suggest that all women living within a particular boundary are all impacted equally by the hazard of interest, without an accurate assessment of individual exposure.

Whereas, women living next to polluted site but this hazard is not located within their spatial unit would not be defined as exposed. Therefore, the larger the spatial unit, the more likely it is that bias will be introduced due to heterogeneity within these units, and ecological fallacy may result.

However, when precise information concerning the individual location is missing ecological studies constitute an appropriate alternative to investigate some hypotheses. These approaches are easy to perform in a short period of time, and at a low cost. In addition, they are less likely to show random variation errors than analytic case-control studies.

Individual approach When the place of the residence of each women is well known, the individual approach is possible. However, incorrect geocoding of both the residential addresses of the pregnant women and the polluted sites may bias the study's findings. Firstly, the process of geocoding may itself introduce bias because geocoding accuracy depends on many characteristics. For instance, accuracy is higher in urban than in rural areas, because rural addresses are frequently reduce to the name of a street (with no number) or to the place name (with no street/ road name) [62]. The result of the geocoding process may bias the study population as several studies revealed that subjects whose addresses were not geocoded tended to be younger, Hispanic and less well-educated than subjects whose addresses were geocoded [39]. However, most casecontrol studies indicated that un-geocoded subjects were equally distributed among cases and controls (for instance the study by Kuhen et al. [34]) - which should result in a non-differential bias, thus biasing the association measure toward the null. However, omission of non-geocoded cases could distort associations in cohort study designs.

As in ecological studies, In individuals approaches including cohort or case-control studies, some misclassification of exposure may result from the used of census tract [35], postcode [49] or zip code [30] to define the location of maternal residence. In addition, census tracts or zip codes might not be valid measures of proximity because they vary considerably in size and are irregular in shape $[28,30,35,49]$.

In contrast with ecological approaches, in individuals approaches the authors may have additional information concerning residential history which may improve the exposure measure of women.

Exposure misclassification may occur where the birth certificate address does not reflect the mother's true residence during the relevant window of fetal development 
$[34,45,63,64]$. To assign exposure, many studies used maternal address at delivery rather than address around conception and during the first trimester, a period of particular relevance and vulnerability for fetal development. Few studies have considered exposure during pregnancy and the preconception period [32, 35, 40]. This can have a particular impact on studies exploring the risk of chromosomal and non-chromosomal congenital malformations, because organogenesis is essentially complete by the end of the first trimester of pregnancy, and most structural birth defects appear during this period [65]. In the case of non-chromosomal abnormalities (conotruncal heart defects, for example) the most critical period is during the first two months after conception [13, 49]. For chromosomal congenital abnormalities, the most appropriate residential exposure windows would include parental residences shortly before or at conception or even grand-maternal residences for some defects if the aberration occurred during maternal meiosis I [32, 33, $49,66]$.

Misclassification of exposure may occur following changes in residence during the pregnancy [33, 49]. In general, studies are unable to take this limitation into account, due to a lack of information as to the pregnant women's mobility [31, 34, 44]. Where available, estimation of residential mobility among pregnant women between conception and delivery differed between a Canadian [67] and a US study [64, 68, 69] and ranged from about $12 \%$ in the former to $32 \%$ in Texas [64]. However, of these, only 50\% moved more than $1 \mathrm{~km}$ away [70] from the initial residence. This residential mobility may vary according to certain individual and contextual characteristics such as age, race, socioeconomic status and other factors. Higher mobility rates during pregnancy have been reported among whites, young mothers [69], less well-educated mothers [68], mothers with lower household income and higher pregnancy body mass index [67] and who lived near a hazardous waste site [71]. Some studies found that young mothers ( $<20$ years) were more likely to move between conception and delivery than older mothers ( $>30$ years) [33, 64]. This means that the exposure misclassification error due to using delivery address might be greater among younger mothers than among older ones, a phenomenon that might result in confounding-because age is also associated with the risk of poor pregnancy outcome.

This type of misclassification error may also tend to reduce the magnitude of estimated effects [68, 72]. Some studies estimate that this would lead, roughly, to a $10 \%$ underestimation of the true excess risk of congenital abnormality related to exposure during early pregnancy [73]. Where studies used case-control analysis, to the extent that residential proximity to a hazardous waste site was misclassified non-differentially among cases and controls, the results would have been biased toward the null [40]. Nevertheless, where authors have restricted their analysis to women who resided at the address noted on the vital record for at least 12 months before delivery or fetal death [74], only a slight increase in the OR was observed-still not significant [40]. On the other hand, in a study of women aged 35+, the association between maternal residence near industrial facilities during the periconceptional period and oral clefts was stronger than for maternal address at delivery [32].

Study design and risk estimate In the ecological studies, the model relating risk to exposure to polluted site at individual level may differ to that at group level [75]. Thus, the relations observed between the variables at the group level (zip code, census block, village) cannot be directly transposed to the individual level $[76,77]$ even if several individual and ecological studies quantify the relation with the same association measure (the odds ratio or the relative risk). Whereas individuals' studies are particularly advantageous to assess the risk around polluted sites. In addition, even among individuals' studies, the different study designs (cohort or case-control) provide various quantitative risk estimates. Therefore, the analysis and the comparison of the impact of living around polluted sites are difficult because of the heterogeneity in study designs even if we know that under certain conditions, when the frequency of the health event is very low, as it the case in the present study (congenital malformation, LBW ...) the OR gives a good estimate of the RR.

\section{Assessment of the risk of pregnancy outcome around polluted sites}

An array of factors will be evoked below. Firstly, the various confounding factors included in the individual studies lead difficult the comparisons between studies. Indeed, some studies did not use any covariates [31], while others adjusted only baby characteristics (sex, year of birth) without maternal characteristics [42-44, 50]. Others studies adjusted on baby and mother characteristics (maternal age, maternal education...) [33, 46], and less often on paternal characteristics $[34,40]$ while others selected four putative confounders, including baby and maternal characteristics and unhealthy behaviors among others (smoking and alcohol use) [29, 30, 32, 35, 36, 40, 55] or healthy behaviors (vitamin use) [35].

An absence of systematic adjustment for commonly known factors may affect the measure of association and thus the comparisons-for instance folic acid supplementation, which is known to decrease the risk of congenital malformation [78]. These risk factors tend to vary across the unit of analysis and if they are coincident with the 
exposure measures, then these spatial confounders will bias the results of the study. In ecological studies, if no individual's data are available, choosing a spatial unit as small as possible will decrease the ecological bias because confounding may be less of a threat and more easily controlled in the analysis.

Secondly, the sample size of any statistical and epidemiological studies may affect the statistical power and led to show either (i) an absence of significant association of excess risk only by lack of power or; (ii) to show a significant association which is not validated because a low statistical power. In our review, we have various sample size from a very small sample ( 92 case of stillbirth in Bhopal study [48]) to large sample $(136,821$ cases of congenital malformation [11]) which can partially explain the diversity of findings even focusing on the study design; for instance, in ecological studies, some studies including 92 case of stillbirth [48] and 302 case of congenital malformations [48] did not reveal any significant excess risk among women living near petrochimical industries. While Cresswell, with 1508 case of congenital malformations, found a weak evidence of relation between prevalence of congenital malformations and residence near waste combustion plant [24]. However, some ecological studies included high sample size, including 136,821 cases of congenital malformation [11], 43,471 stillbirth [45], and found also significant weak associations.

In the individual studies, the authors investigated a more important sample size (7242 cases of fetal death [56], 6538 cases of PTB [55], except few studies which included only 63 cases of VLBW, 353 cases of LBW [29]. However, in case-control design study, several of them included no more than one control by case $[12,35,54]$; for instance: 7304 cases and 7834 control, [54], 507 cases and 517 control [35]. The number of controls per case is yet recognized to be a simple way to increase statistical power of studies.

While, other case-control included more than 3 control by cases [13, 32, 34, 39], for instance: 1244 case and 4368 control [13], 1289 case and 4965 control [32].

All the features of the studies describe above-such as study population, study design, sample size, the classification and definition of reproductive outcome, exposure assessment and confounding factors-could impact, independently or in combination, the quality of each study itself and also their comparison in our systematic review.

\section{Future research}

On the basis of this analysis of the limitations of the current body of research and of theoretical and methodological considerations, below we describe some suggestions for improvements to a research agenda.

\section{Data accuracy}

Lack of address-specific household data is a major impediment in assessing the health impact of residential proximity to polluted sites. Aggregated health data are most often not sufficiently fine-grained. While individual health data are more relevant, at least data collected at a fine resolution scale (such as census block) would improve the quality of the information. Neither is the spatial resolution of polluted site data generally precise. Site boundaries could be digitized instead of using simple points as location of exposure source, particularly when studying hazardous waste sites such as landfills.

\section{Appropriate geostatistical approaches}

Although environmental modeling is relatively cumbersome, labor-intensive, computer-intensive and requires extensive data input, it is still held out as the gold standard for environmental or health impact assessment. Some reliable alternative methods could be developed-preferably geostatistical approaches that are well-integrated or closely-coupled with GIS approaches-to estimate the contribution of various sources to total exposure, and to optimize exposure assessment. This calls for multidisciplinary teams having expertise in GIS, epidemiology, environmental science and statistical modeling.

In addition, in future studies, emphasis could be placed on the selection of focused-cluster test recognized to be more appropriate to spatial pattern of environmental exposure. More precisely, these spatial approaches have been designed and used to detect clusters reflecting a particular spatial pattern [79]; one that centers around the polluted sites and declines with increasing distance from the source.

Instead of investigating spatial data with common but rough approach (which is based on a circle of fixed radius around the point source with arbitrary size chosen by default and consist in the comparison of the frequency of cases inside with outside the buffer), the futures studies could use inferential method such as focused methods design to detect focused clustering around polluted site under the hypothesis that the risk of disease is high close to polluted site.

These spatial approaches use distance as a surrogate for exposure and assess whether cases are closer to the source than expected. Compared to other spatial methods, one advantage of these methods is that they address a specific hypothesis of concern and, because of their specificity, have increased sensitivity. Among these approaches, some authors proposed to use binary isotonic regression, known as Stone's MLR test. One useful feature of isotonic regression is that the test result does not depend on whether one uses distance from the source of a measure of exposure for the analysis, as 
long as the exposure is decreasing with distance from the source [80].

\section{Multi-hazard approaches}

Most studies to date have looked at only one or two environmental hazards at a given point in time. Investigating the cumulative and synergistic impacts of the variety of chemical and non-chemical hazards and nuisances could help understand whether these impacts might be larger than currently acknowledged.

\section{Enhanced exposure assessment}

Because people do not spend their whole lives at home, future research should strive to incorporate residential mobility and daily commuting associated with occupational (or school) activities in exposure assessment. Further, the time window of exposure should be appropriate for each adverse reproductive outcome, from life-threatening teratogenic effects to weight or term at birth. This means that focusing on the preconceptional period, the first trimester of pregnancy or later, as most relevant.

\section{Investigation of social inequalities}

Today, there are significant gaps in our understanding of how disparities in exposure levels according to individual or contextual socioeconomic status (the 'environmental justice' issue) may or may not interact with other risk factors associated with social deprivation, such as poor access to health care, a low level of physical activity or high prevalence of smoking. Future studies on reproductive outcome in relation to proximity to polluted sites might accommodate relevant study designs and data analyses approaches to explore the assumption that social deprivation might represent an effect modifier for exposure to hazardous substances in such settings.

\section{Conclusions and public policy perspectives}

Despite improvements to the control of emission measurements in industrialized countries since the 1990s, ('Superfund' in the USA, 'IPCC' in the European Union and similar provision), there are suggestive evidences that residential proximity to polluted sites (including landfills, hazardous waste sites and industrial facilities) might contribute to adverse reproductive outcomes, especially congenital malformation and low birth weight-However, no studies show significant excess risk of mortality including fetal death, neonatal or infant mortality and stillbirth. In order to focus on preventive actions and provide useful tools, we need to better understand and interpret our findings, considering weaknesses which could affect the strength of associations, yield limitations in comparisons or impede the formulation of accurate conclusions. However, our study should trigger hypotheses which would recommend strengthening the rules governing industrial emissions and industrial waste management, and reinforce land-use planning with regard to the most polluted sites.

\section{Authors' contributions}

WK has performed the systematic review, conducted the analyses of epidemiological studies selected, drafted the article. CP has contributed to the drafting of article and to its finalization. SD, PI of the Equit'Area Project examining the role of environmental exposures on health inequalities, has followed up the general labor, contributed to the analysis, interpretation of results, writing the paper and its finalization. DZN, Head of the environmental and occupational health department at the EHESP, guarantees quality assurance and rigor in the systematic review, has reviewed the drafts of the article and contributed to its finalization. All authors read and approved the final manuscript.

\section{Author details \\ ${ }^{1}$ LIVE UMR 7362 CNRS (Laboratoire Image Ville Environnement), University of Strasbourg, 3 Rue de l'argonne, 6700 Strasbourg, France. ${ }^{2}$ Department of Environmental and Occupational Health, School of Public Health (EHESP), Rennes and Sorbonne Paris Cité, Paris, France. ${ }^{3}$ INSERM U1085-IRSET - \\ Research Institute of Environmental and Occupational Health, Rennes, France. \\ ${ }^{4}$ Lorraine University, Vandoeuvre-les-Nancy, France. ${ }^{5}$ Department of Quan- titative Methods in Public Health, School of Public Health (EHESP), Rennes and Sorbonne Paris Cité, Paris, France. ${ }^{6}$ Department of Social Epidemiology, Sorbonne Universités, UPMC Univ Paris 06, INSERM, Institut Pierre Louis d’Epidémiologie et de Santé Publique (UMRS 1136), Paris, France.}

\section{Acknowledgements}

We thank Jane Roffe for critical reading and editing of the manuscript.

\section{Competing interests}

The authors declare that they have no competing interests.

\section{Funding}

This work was supported by the Foundation de France.

Received: 3 January 2017 Accepted: 25 April 2017

Published online: 30 May 2017

References

1. Vrijheid M, Dolk H, Armstrong B, Boschi G, Busby A, Jorgensen T, et al. Hazard potential ranking of hazardous waste landfill sites and risk of congenital anomalies. Occup Environ Med. 2002;59:768-76.

2. Vrijheid M. Health effects of residence near hazardous waste landfill sites: a review of epidemiologic literature. Environ Health Perspect. 2000;108(Suppl 1):101-12.

3. Sram RJ, Binková B, Dejmek J, Bobak M. Ambient air pollution and pregnancy outcomes: a review of the literature. Environ Health Perspect. 2005;113:375-82.

4. Zeka A, Melly SJ, Schwartz J. The effects of socioeconomic status and indices of physical environment on reduced birth weight and preterm births in Eastern Massachusetts. Environ Health. 2008;7:60.

5. Gehring U, Tamburic L, Sbihi H, Davies HW, Brauer M. Impact of noise and air pollution on pregnancy outcomes. Epidemiology. 2014;25:351-8.

6. Brauer M, Lencar C, Tamburic L, Koehoorn M, Demers P, Karr C. A cohort study of traffic-related air pollution impacts on birth outcomes. Environ Health Perspect. 2008;116:680-6.

7. Brender JD, Maantay JA, Chakraborty J. Residential proximity to environmental hazards and adverse health outcomes. Am J Public Health. 2011;101:S37-52.

8. Satoh K, Nagai F, Aoki N. Several environmental pollutants have binding affinities for both androgen receptor and estrogen receptor a. J Health Sci. 2001;47:495-501.

9. Rzymski P, Tomczyk K, Rzymski P, Poniedziałek B, Opala T, Wilczak M. Impact of heavy metals on the female reproductive system. Ann Agric Environ Med. 2015;22:259-64. 
10. Sharpe RM, Irvine DS. How strong is the evidence of a link between environmental chemicals and adverse effects on human reproductive health? BMJ. 2004:328:447-51.

11. Elliott P, Richardson S, Abellan JJ, Thomson A, de Hoogh C, Jarup L, et al. Geographic density of landfill sites and risk of congenital anomalies in England. Occup Environ Med. 2009;66:81-9.

12. Orr M, Bove F, Kaye W, Stone M. Elevated birth defects in racial or ethnic minority children of women living near hazardous waste sites. Int J Hyg Environ Health. 2002;205:19-27.

13. Langlois PH, Brender JD, Suarez L, Zhan FB, Mistry JH, Scheuerle A, et al. Maternal residential proximity to waste sites and industrial facilities and conotruncal heart defects in offspring. Paediatr Perinat Epidemiol. 2009;23:321-31.

14. The Comprehensive Environmental Response, Compensation, and Liability Act (CERCLA). Law, December 11, 1980. Available at: http://www.epa. gov/superfund/policy/cercla.htm.

15. Pollution Prevention act, 1990, 42 U.S.C. 13101 and 13102, s/s and seq. (1990). Available at: http://www.epa.gov/p2/pubs/p2policy/act1990.htm.

16. Directive $96 / 31 / C E$ of the council of 24 September 1996 concerning integrated pollution prevention and control (IPPC). Directive of the European Union available at: http://europa.eu/legislation_summaries/ environment/waste_management//28045_en.htm.

17. The Law No 76-663 of 19 July 1976 on the classification of installations for the protection of the environment (ICPE). http://www.legifrance.gouv.fr/ affichTexte.do?cidTexte $=$ JORFTEXT000000684771\&categorieLien=cid.

18. The pollution Prevention and Control (England and Wales) (Amendment) regulations 2002, statutory instrument 2002 No. 275. Available at: http:// www.legislation.gov.uk/uksi/2002/275/introduction/made.

19. Moher D, Liberati A, Tetzlaff J, Altman DG, PRISMA Group. Preferred reporting items for systematic reviews and meta-analyses: the PRISMA statement. Ann Intern Med. 2009;151:264-9 (W64)

20. Moher D, Liberati A, Tetzlaff J, Altman DG, The PRISMA Group. Preferred reporting items for systematic reviews and meta-analyses: the PRISMA statement. PLoS Med. 2009;6(6):e1000097. doi:10.1371/journal. pmed1000097.

21. Fielder HM, Poon-King CM, Palmer SR, Moss N, Coleman G. Assessment of impact on health of residents living near the Nant-y-Gwyddon landfill site: retrospective analysis. BMJ. 2000;320:19-22.

22. Yauck JS, Malloy ME, Blair K, Simpson PM, McCarver DG. Proximity of residence to trichloroethylene-emitting sites and increased risk of offspring congenital heart defects among older women. Birth Defects Res. Part A Clin Mol Teratol. 2004;70:808-14.

23. Shaw GM, Schulman J, Frisch JD, Cummins SK, Harris JA. Congenital malformations and birthweight in areas with potential environmental contamination. Arch Environ Health. 1992;47:147-54.

24. Cresswell PA, Scott JES, Pattenden S, Vrijheid M. Risk of congenital anomalies near the Byker waste combustion plant. J Public Health Med. 2003;25:237-42

25. Eizaguirre-García D, Rodríguez-Andrés C, Watt GCM. Congenital anomalies in Glasgow between 1982 and 1989 and chromium waste. J Public Health. 2000;22:54-8.

26. Kloppenborg SC, Brandt UK, Gulis G, Ejstrud B. Risk of congenital anomalies in the vicinity of waste landfills in Denmark; an epidemiological study using GIS. Cent Eur J Public Health. 2005;13:137-43.

27. Berry M, Bove F. Birth weight reduction associated with residence near a hazardous waste landfill. Environ Health Perspect. 1997;105:856-61.

28. Baibergenova A, Kudyakov R, Zdeb M, Carpenter DO. Low birth weight and residential proximity to PCB-contaminated waste sites. Environ Health Perspect. 2003;111:1352-7.

29. Gilbreath S, Kass PH. Adverse birth outcomes associated with open dumpsites in Alaska Native Villages. Am J Epidemiol. 2006;164:518-28.

30. Sosniak WA, Kaye WE, Gomez TM. Data linkage to explore the risk of low birthweight associated with maternal proximity to hazardous waste sites from the National Priorities List. Arch Environ Health. 1994:49:251-5.

31. Malik S, Schecter A, Caughy M, Fixler DE. Effect of proximity to hazardous waste sites on the development of congenital heart disease. Arch Environ Health. 2004;59:177-81.

32. Brender JD, Zhan FB, Suarez L, Langlois PH, Moody K. Maternal residential proximity to waste sites and industrial facilities and oral clefts in offspring. J Occup Environ Med. 2006;48:565-72.
33. Brender JD, Zhan FB, Langlois PH, Suarez L, Scheuerle A. Residential proximity to waste sites and industrial facilities and chromosomal anomalies in offspring. Int J Hyg Environ Health. 2008;211:50-8.

34. Kuehn CM, Mueller BA, Checkoway H, Williams M. Risk of malformations associated with residential proximity to hazardous waste sites in Washington State. Environ Res. 2007;103:405-12.

35. Croen LA, Shaw GM, Sanbonmatsu L, Selvin S, Buffler PA. Maternal residential proximity to hazardous waste sites and risk for selected congenital malformations. Epidemiology. 1997;8:347-54.

36. Gilbreath S, Kass PH. Fetal and neonatal deaths and congenital anomalies associated with open dumpsites in Alaska Native villages. Int J Circumpolar Health. 2006;65:133-47.

37. Geschwind SA, Stolwijk JA, Bracken M, Fitzgerald E, Stark A, Olsen C, et al. Risk of congenital malformations associated with proximity to hazardous waste sites. Am J Epidemiol. 1992;135:1197-207.

38. Marshall EG, Gensburg LJ, Deres DA, Geary NS, Cayo MR. Maternal residential exposure to hazardous wastes and risk of central nervous system and musculoskeletal birth defects. Arch Environ Health. 1997;52:416-25.

39. Suarez L, Brender JD, Langlois PH, Zhan FB, Moody K. Maternal exposures to hazardous waste sites and industrial facilities and risk of neural tube defects in offspring. Ann Epidemiol. 2007;17:772-7.

40. Mueller BA, Kuehn CM, Shapiro-Mendoza CK, Tomashek KM. Fetal deaths and proximity to hazardous waste sites in Washington State. Environ Health Perspect. 2007;115:776-80.

41. Boyle E, Johnson H, Kelly A, McDonnell R. Congenital anomalies and proximity to landfill sites. Ir Med J. 2004;97:16-8.

42. Dummer TJB, Dickinson HO, Parker L. Adverse pregnancy outcomes near landfill sites in Cumbria, northwest England, 1950-1993. Arch Environ Health. 2003;58:692-8.

43. Dummer TJB, Dickinson HO, Parker L. Prevalence of adverse pregnancy outcomes around hazardous industrial sites in Cumbria, north-west England, 1950-93. Paediatr Perinat Epidemiol. 2003;17:250-5.

44. Dummer TJB, Dickinson HO, Parker L. Adverse pregnancy outcomes around incinerators and crematoriums in Cumbria, north west England, 1956-93. J Epidemiol Community Health. 2003;57:456-61.

45. Elliott P, Briggs D, Morris S, de Hoogh C, Hurt C, Jensen TK, et al. Risk of adverse birth outcomes in populations living near landfill sites. BMJ. 2001;323:363-8.

46. Palmer SR, Dunstan FDJ, Fielder H, Fone DL, Higgs G, Senior ML. Risk of congenital anomalies after the opening of landfill sites. Environ Health Perspect. 2005;113:1362-5.

47. Morris SE, Thomson AO, Jarup L, de Hoogh C, Briggs DJ, Elliott P. No excess risk of adverse birth outcomes in populations living near special waste landfill sites in Scotland. Scott Med J. 2003:48:105-7.

48. Bhopal RS, Tate JA, Foy C, Moffatt S, Phillimore PR. Residential proximity to industry and adverse birth outcomes. Lancet. 1999;354:920-1.

49. Jarup L, Morris S, Richardson S, Briggs D, Cobley N, de Hoogh C, et al. Down syndrome in births near landfill sites. Prenat Diagn. 2007:27:1191-6.

50. Morgan OWC, Vrijheid M, Dolk H. Risk of low birth weight near EUROHAZCON hazardous waste landfill sites in England. Arch Environ Health. 2004;59:149-51.

51. Vrijheid M, Dolk H, Armstrong B, Abramsky L, Bianchi F, Fazarinc I, et al. Chromosomal congenital anomalies and residence near hazardous waste landfill sites. Lancet. 2002;359:320-2.

52. Dolk H, Vrijheid M, Armstrong B, Abramsky L, Bianchi F, Garne E, et al. Risk of congenital anomalies near hazardous-waste landfill sites in Europe: the EUROHAZCON study. Lancet. 1998;352:423-7.

53. Castelló A, Río I, García-Pérez J, Fernández-Navarro P, Waller LA, Clennon $J A$, et al. Adverse birth outcomes in the vicinity of industrial installations in Spain 2004-2008. Environ Sci Pollut Res Int. 2013;20:4933-46.

54. Goldberg MS, Goulet L, Riberdy H, Bonvalot Y. Low birth weight and preterm births among infants born to women living near a municipal solid waste landfill site in Montreal, Quebec. Environ Res. 1995;69:37-50.

55. Dodds L, Seviour R. Congenital anomalies and other birth outcomes among infants born to women living near a hazardous waste site in Sydney, Nova Scotia. Can J Public Health. 2001;92:331-4.

56. Tango T, Fujita T, Tanihata T, Minowa M, Doi Y, Kato N, et al. Risk of adverse reproductive outcomes associated with proximity to municipal solid waste incinerators with high dioxin emission levels in Japan. J Epidemiol. $2004 ; 14: 83-93$ 
57. Bentov Y, Kordysh E, Hershkovitz R, Belmaker I, Polyakov M, Bilenko N, et al. Major congenital malformations and residential proximity to a regional industrial park including a national toxic waste site: an ecological study. Environ Health. 2006:5:8.

58. Nuckols JR, Ward MH, Jarup L. Using geographic information systems for exposure assessment in environmental epidemiology studies. Environ Health Perspect. 2004;112:1007-15.

59. Liu F. Environmental justice analysis: theories, methods, and practice. New York: CRC Press; 2001

60. WHO. Methods of assessing the risk to health from exposure to hazards released from waste landfills. Report from a WHO meeting Lodz, Poland 10-12 April, 2000. Bilthoven, WHO Regional Office for Europe, European Centre for Environment and Health: The Netherlands. 2000.

61. James L, Matthews I, Nix B. Spatial contouring of risk: a tool for environmental epidemiology. Epidemiology. 2004;15:287-92.

62. Hurley SE, Saunders TM, Nivas R, Hertz A, Reynolds P. Post office box addresses: a challenge for geographic information system-based studies. Epidemiology. 2003;14:386-91.

63. Schulman J, Selvin S, Shaw GM, Malcoe LH. Exposure misclassification due to residential mobility during pregnancy in epidemiologic investigations of congenital malformations. Arch Environ Health. 1993;48:114-9.

64. Canfield MA, Ramadhani TA, Langlois PH, Waller DK. Residential mobility patterns and exposure misclassification in epidemiologic studies of birth defects. J Expo Sci Environ Epidemiol. 2006;16:538-43.

65. Polifka JE, Friedman JM. Clinical teratology: identifying teratogenic risks in humans. Clin Genet. 1999;56:409-20.

66. Pacchierotti F, Adler I-D, Eichenlaub-Ritter U, Mailhes JB. Gender effects on the incidence of aneuploidy in mammalian germ cells. Environ Res. 2007;104:46-69.

67. Fell DB, Dodds L, King WD. Residential mobility during pregnancy. Paediatr Perinat Epidemiol. 2004;18:408-14.

68. Shaw GM, Malcoe LH. Residential mobility during pregnancy for mothers of infants with or without congenital cardiac anomalies: a reprint. Arch Environ Health Int J. 1992;47:236-8.

69. Khoury MJ, Stewart W, Weinstein A, Panny S, Lindsay P, Eisenberg M. Residential mobility during pregnancy: implications for environmental teratogenesis. J Clin Epidemiol. 1988;41:15-20.
70. Dolk H. The influence of migration in small area studies of environment and health-migration during pregnancy. ONS Longitudinal Stud Update. 1997;17:6-8.

71. Yoon PW, Rasmussen SA, Lynberg MC, Moore CA, Anderka M, Carmichael $\mathrm{SL}$, et al. The national birth defects prevention study. Public Health Rep. 2001;116(Suppl 1):32-40.

72. Copeland KT, Checkoway H, McMichael AJ, Holbrook RH. Bias due to misclassification in the estimation of relative risk. Am J Epidemiol. 1977;105:488-95.

73. Asmstrong B., Gleave S, Wilkinson P. The impact of migration on disease rates in areas with previous environmental exposures. Epidemiology [Internet]. 1996 [cited 2015 Feb 3];7. Available from: http://journals.Iww. com/epidem/Fulltext/1996/07001/THE_IMPACT_OF_MIGRATION_ON_ DISEASE_RATES_IN_AREAS.281.aspx.

74. Hertz-Picciotto I, Pastore LM, Beaumont JJ. Timing and patterns of exposures during pregnancy and their implications for study methods. Am J Epidemiol. 1996;143:597-607.

75. Elliott P, Savitz DA. Design issues in small-area studies of environment and health. Environ Health Perspect. 2008;116:1098-104.

76. Elliot A, Wakefield J. Bias and confounding in spatial epidemiology. In: Elliott P, Wakefield J, Best N, Briggs DJ, editors. Spatial epidemiology: methods and applications. Methods and applications. Oxford: Oxford University Press; 2000. p. 68-84.

77. Greenland S. Divergent biases in ecologic and individual-level studies. Stat Med. 1992;11:1209-23.

78. Wilcox AJ, Lie RT, Solvoll K, Taylor J, McConnaughey DR, Abyholm F, et al. Folic acid supplements and risk of facial clefts: national population based case-control study. BMJ. 2007;334:464.

79. Kulldorff M, Tango M, Park PJ. Power comparisons for disease clustering tests. Comput Stat Data Anal. 2003;42(4):665-84.

80. Kulldorff K. Statistical methods for spatial epidemiology: test for randomness. In: Löytönen M, Gatrell A, editors. GIS and Health. London: Taylor \& Francis; 1998. p. 49-62.

\section{Submit your next manuscript to BioMed Central and we will help you at every step:}

- We accept pre-submission inquiries

- Our selector tool helps you to find the most relevant journal

- We provide round the clock customer support

- Convenient online submission

- Thorough peer review

- Inclusion in PubMed and all major indexing services

- Maximum visibility for your research

Submit your manuscript at www.biomedcentral.com/submit 